\title{
Informal unemployment and education
}

*Correspondence: bl.eco@cbs.dk ${ }^{2}$ Copenhagen Business School, Frederiksberg, Denmark

Full list of author information is available at the end of the article

\begin{abstract}
This paper develops a four-sector equilibrium search and matching model with informal sector employment opportunities and educational choice. We show that underground activities reduce educational attainments if informal employment opportunities mainly are available for low-educated workers. A more zealous enforcement policy will in this case improve educational incentives as it reduces the attractiveness of remaining a low-educated worker. However, unemployment also increases. Characterizing the optimal enforcement policies, we find that relatively more audits should be targeted towards the sector employing low-educated workers; elsewise, a too low stock of educated workers is materialized.
\end{abstract}

JEL Classification: H26, I21, J64

Keywords: Tax evasion, The informal sector, Education, Matching, Unemployment

\section{Introduction}

Researchers have been puzzled by the fact that observed tax evasion in high-income countries, despite low audit rates and fairly modest fines, is substantially lower than what is predicted by theory. Andreoni et al. (1998) argue that this discrepancy is most likely explained by non-economic factors, such as morality, guilt, and shame. However, Kleven et al. (2011), who conducted a large field experiment on individual tax filers in Denmark, suggest that this discrepancy is explained by the degree of third-party reporting. As incomes for individuals are not self-reported, rather reported by a third party such as the employer, it is difficult, and thus costly, to evade taxes. These costs, both due to third-party reporting, or even morality, guilt, or shame, tend to reduce the profitability of evading taxes and limit the size of the informal sector, although the expected punishment fees are low relative to taxes.

In this paper, we argue that these types of costs may explain why highly educated workers to a lesser extent evade taxes and work informally than low-educated workers. If highly educated workers to a smaller extent work in industries which handle cash payments and to a larger extent are subject to third-party reporting, it will be more difficult, and thus more costly, for these workers to evade taxes.

This is consistent with data. Evidence indicates that manual workers, or workers with a lower level of formal education, to a substantially higher degree face informal employment opportunities compared to highly educated workers. Pedersen (2003), using the same questionnaire design for Germany, Great Britain, Denmark, Norway, and Sweden, confirms that skilled blue collar workers carry out more informal market activities than

(c) 2016 The Author(s) Open Access This article is distributed under the terms of the Creative Commons Attribution 4.0 International License (http://creativecommons.org/licenses/by/4.0/), which permits unrestricted use, distribution, and reproduction in any medium, provided you give appropriate credit to the original author(s) and the source, provide a link to the Creative Commons license, and indicate if changes were made. 
others. Figure 1 shows the extent of informal activities in the five countries by industry. Most informal work are carried out in the construction sector, followed by the agricultural sector, hotels, and restaurants. This pattern is also confirmed for Denmark, by Hvidtfeldt et al. (2011), and for Germany, by Haigner et al. (2011), using representative survey data.

Furthermore, performing logistic regressions for the five countries, Pedersen (2003) confirms that the likelihood of informal market activities falls with the length of education. In addition, Boeri and Garibaldi (2005) show for Italy that mainly workers at the lower end of the skill distribution engage in informal activities.

The fact that mainly low-educated workers seem to work in the informal sector suggests that the choice of educational attainment is potentially distorted. Informal employment opportunities foregone with education may simply reduce the incentives for workers to acquire education.

The aim of this paper is to investigate the equilibrium impact of underground activities on labour market outcomes and educational attainment in high-income countries, as well as to characterize the optimal enforcement policy. Although harsher punishment policies may correct for a too low stock of educated workers, total unemployment may increase with such policy. In fact, we have little guidance from research to what extent formal sector jobs replace jobs in the underground economy as those jobs disappear with stricter informal sector punishment.

For this purpose, we develop a four-sector general equilibrium model featuring matching frictions on the labour market. Unemployed workers search for jobs in both a formal and an informal sector, and workers decide whether or not to acquire higher education based on their ability levels. Education is considered to be a once and for all investment in human capital and takes place as soon as the worker enters the labour market. ${ }^{1}$

In order to isolate the mechanisms and increase the transparency of the model, we keep the differences between the formal and informal sectors at a minimum. ${ }^{2}$ The only dissimilarities between the sectors are that taxes are not paid in the latter and that productivity in the formal sector may be higher than productivity in the informal sector. Instead of paying taxes, informal sector firms have to pay a fine in case they are hit by an audit and detected as tax cheaters. In addition, firms in the informal sector are assumed to face concealment costs. In our model, we let concealment costs capture costs associated with

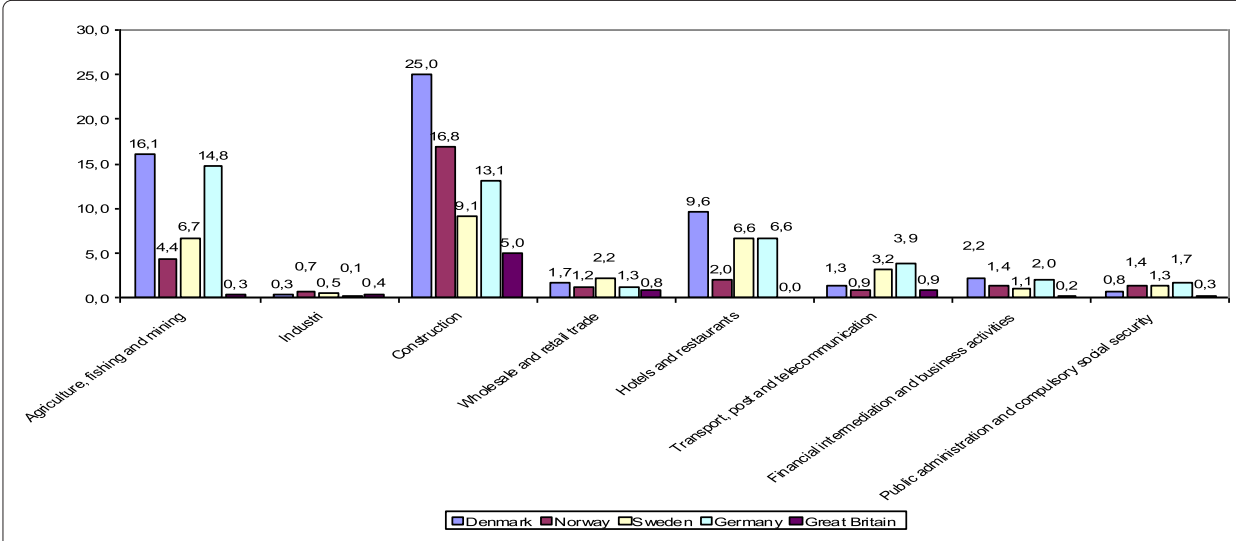

Fig. 1 Fraction of informal sector work by industry. Pedersen (2003) 
concealing taxable income due to third-party reporting or even morality, guilt, or shame. The costs reduce the profitability of evading taxes and limit the size of the informal sector although the expected punishment fees are low relative to taxes. In line with Kleven et al. (2011), we also let these costs be higher the more income that is hidden from the tax authorities.

We find that underground activities reduce the incentives to acquire higher education if informal employment opportunities mainly are available to low-educated workers. More zealous enforcement policies will in this case improve educational incentives as these reduce the attractiveness of remaining a low-educated worker. However, if also highly educated workers to a large extent are exposed to informal employment opportunities, the incentives to acquire higher education may fall with stricter enforcement policies as underground work pays off better to workers with high productivity. Moreover, we find that actual unemployment most likely increases, although the official unemployment falls. Finally, characterizing the optimal enforcement policies, we find that relatively more audits should be targeted towards the sector employing low-educated workers; elsewise, the outcome is a too low stock of educated workers.

The present paper extends the strand of tax evasion literature which departs from the assumption of imperfectly competitive labour markets by incorporating involuntary unemployment through the inclusion of search frictions. ${ }^{3}$ See, for example, Fugazza and Jacques (2004), Boeri and Garibaldi (2005), and Kolm and Larsen (2006) who also model underground activities in high-income countries. These studies focus on labour market outcomes and rely on asymmetries between the formal and the informal sector, such as heterogeneity in morality, in order to explain the co-existence of a formal and an informal sector.

There are also numerous studies based on search theoretical frameworks investigating issues of informal employment from the point of view of low- and middle-income countries. As one can argue that the nature of the informal sector can be quite different in low- and middle-income countries compared to high-income countries, the modelling strategies usually differ in these set-ups. As pointed out by La Porta and Shleifer (2014), the informal sector in low- and middle-income countries is usually huge and contains small, unproductive, and stagnant firms. Moreover, the informal sector in this literature is usually seen as an unregulated sector.

For an example, taking a Latin American perspective, see Albrecht et al. (2009) that accounts for worker heterogeneity and considers the impact of payroll taxes and severance pay on unemployment in the presence of an informal sector. The informal sector can be seen as an unregulated sector which is not affected by payroll taxes and other formal policies. ${ }^{4}$ The recent study by Meghir et al. (2015) takes a slightly different modelling approach in its focus on underground activities in Brazil as the paper considers on-thejob-search and firm heterogeneity. Workers may search for jobs both in the formal and the informal sector, and search frictions make it profitable for firms to start both types of jobs.

The paper is organized as follows. In Section 2, we provide an empirical background and motivation for the paper. In Section 3, the model is set up. Section 4 offers a comparative statics analysis of an increase in the relative punishment of informal activities. Section 5 considers optimal policy, and finally, Section 6 concludes. 


\section{Background and motivation}

As individuals engaged in underground work do not wish to be identified, it is notoriously difficult to collect accurate information about these activities. For natural reasons, we therefore have limited knowledge about the empirical relationships between informal activities and other economic outcomes.

In this section, we construct a cross-sectional data set of 24 OECD countries to investigate the relationships between factors affecting underground activities and educational outcomes. All OECD countries are included in the sample provided that we have data on the size of the informal sector and information on the legal and regulatory framework for the purpose of tax compliance collected by the Global Forum on Transparency and Exchange of Information for Tax Purposes (OECD 2012).

Since the informal economy cannot directly be measured, one has to rely on indicators that capture informal sector activities in order to estimate the size of the sector. Here we use the most recent estimates derived by Schneider et al. (2010). Instead of using a method which assumes that a single factor or indicator can capture all activities in the informal sector, such as the currency demand approach or the electricity approach, they estimate the size of the informal sector using a method which includes multiple causes and indicators of the informal sector. ${ }^{5}$ Figure 2 provides a picture of how large the informal sector is in relation to GDP in the different countries.

If, as we argue, informal employment opportunities are foregone with higher education, we should observe a lower stock of educated workers in countries where it is more profitable to work in the underground economy. Thus, countries with less strict enforcement policies or lower concealment costs relative to the tax burden should have a smaller stock of highly educated workers.

To measure the costs of informal sector work in a country, we construct a variable based on the legal and regulatory framework on the availability of, and access to, information of importance for tax compliance. The data used is collected by the Global Forum on Transparency and Exchange of Information for Tax Purposes (OECD 2012). The Global Forum has set out a large number of standards in order to increase tax compliance, and through

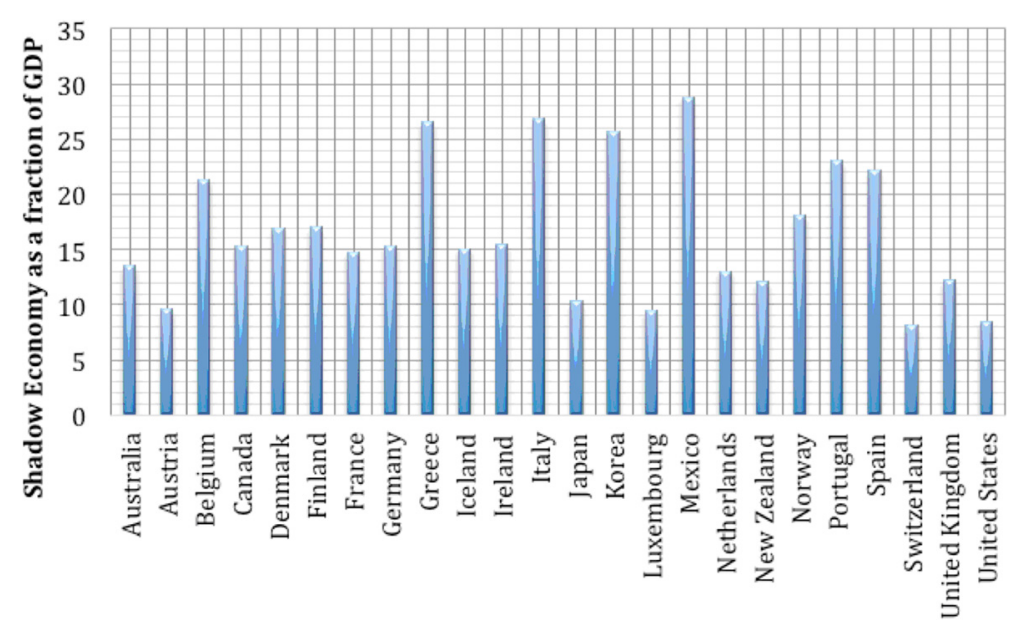

Fig. 2 The size of the shadow economy as a fraction of GDP for each country in 2007 
a process of peer reviewing, the Forum assesses the legal and administrative framework in each member country. More specifically, the peer-reviewing process provides information if the standards are "in place", "in place but there is need for improvements", and "not in place". From this information, we construct an index capturing the costs of evading taxes. $^{6}$

The cost of evading taxes needs to be related to the cost of not evading taxes. ${ }^{7}$ We let these costs be captured by the tax wedge of total labour costs to the employer relative to the corresponding net take-home pay for the average single worker without children. This data from the OECD Taxing Wages database provides unique information on the income taxes paid by workers and the family benefits received in the form of cash transfers as well as the social security contributions and payroll taxes paid by their employers, for each of the OECD countries.

Figure 3 plots the percentage of the total population, 25-64 years old, holding a tertiary education in 2007 (OECD 2012) against our measure for the cost of evading taxes relative to not evading taxes. Consistent with our hypothesis, we observe a positive correlation between the measures; the less attractive it is to work in the informal sector, the more workers will choose a higher education.

In Fig. 4, the aim is to see if the relative cost of evading taxes is negatively correlated with the size of the informal sector. Indeed, we observe a negative correlation between the size of the underground economy as a fraction of GDP and the percentage of the 25-64 years old of the population holding a tertiary education. Thus, economies where the informal sector is more extensive also tend to be economies where a lower fraction of the population educates themselves.

Clearly, as it is challenging to get an accurate measure of the size of the informal sector and, as we have done here, to get a measure of the costs of evading taxes, this section only serves to provide correlations between the variables in focus. To identify causal relationships between, on the one hand, tax and punishment policies and, on the other hand, educational outcomes is giving the available data an overwhelming task. Next, we build an equilibrium model to investigate these relationships, as well as to pin down the mechanisms.

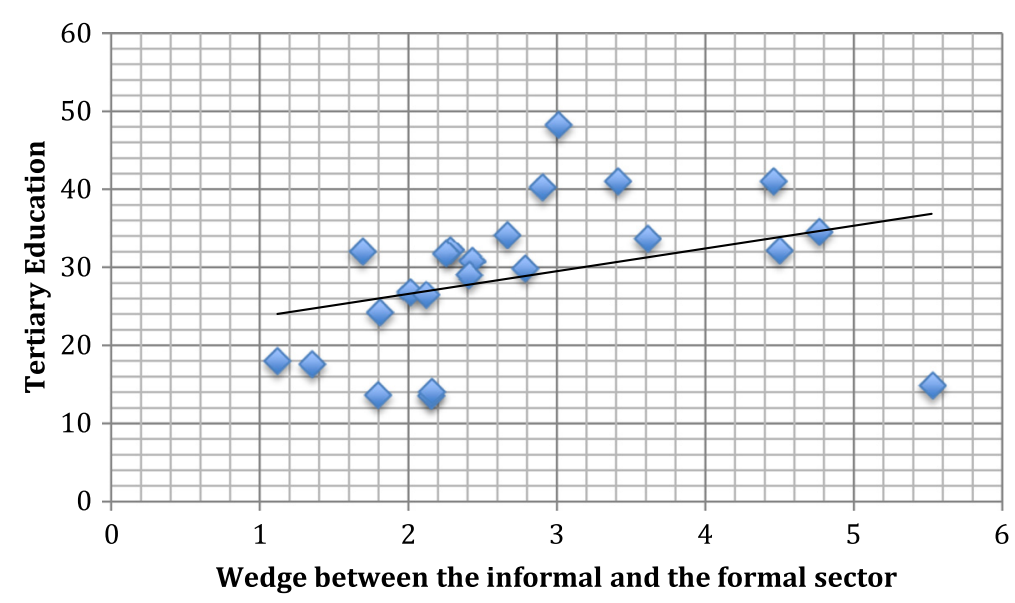

Fig. 3 Fraction of 25-64 years old with tertiary education as a function of the wedge between the informal and the formal sector for 2007 


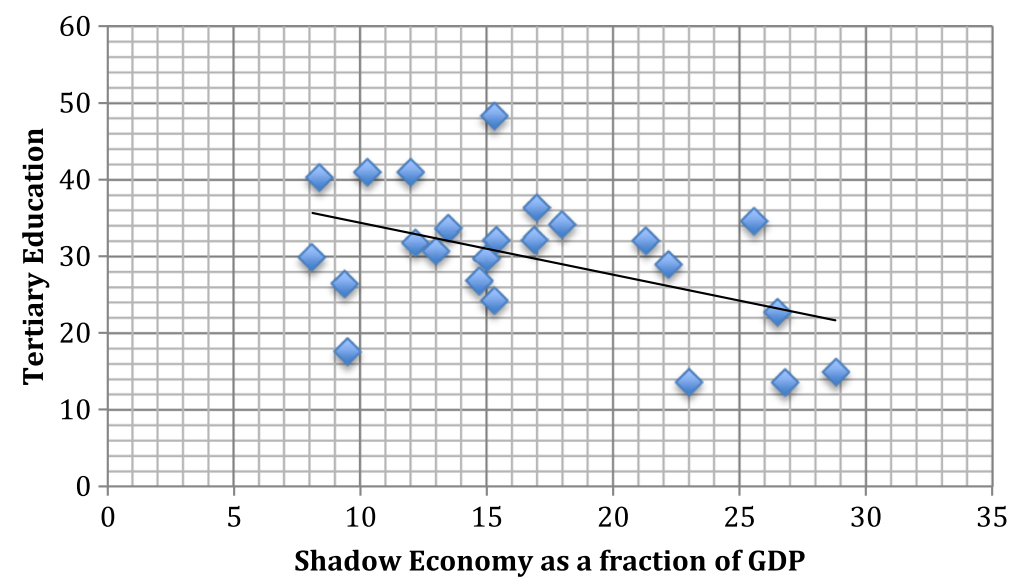

Fig. 4 Fraction of 25-64 years old with tertiary education as a function of the size of the shadow economy as a fraction of GDP in 2007

\section{The model}

This section develops a four-sector general equilibrium model with formal and informal sector employment opportunities and educational choice. Workers differ in the ability to acquire education. Abilities, $e$, are uniformly distributed between 0 and $1, e \in[0,1]$, and the cost of higher education, $c(e)$, is decreasing in ability. Thus, workers with a high level of ability will find it more than worthwhile to invest in higher education, whereas workers with low ability will not. Workers not attaining higher education will from now on be referred to as manual workers. Both manual and highly educated workers allocate search effort optimally between the formal and the informal sector. Once matched with a firm, they bargain over the wage. The economy thus consists of four sectors: the formal and informal sectors for manual workers (denoted $F, m$ and $I, m$ ) and the formal and informal sectors for highly educated workers (denoted $F, h$ and $I, h$ ).

\subsection{Matching}

Manual and highly educated workers search for jobs in both a formal and an informal sector. For simplicity, we assume that only unemployed workers search for jobs. This is a simplification, i.e. we do not acknowledge that the connection to the labour market given by working in the formal or informal sector may bring about job opportunities not available while unemployed. The matching functions for the four categories of jobs are given by $X_{l}^{j}=\left(v_{l}^{j}\right)^{\frac{1}{2}}\left(\left(\sigma_{l}^{j}\right)^{\gamma} u_{l}\right)^{\frac{1}{2}}$, where $X_{l}^{j}$ is the sectorial matching rate, $v_{l}^{j}$ is the sectorial vacancy rate, and $u_{l}$ is the unemployment rate and $j=F, I$ and $l=m, h$. The rates are defined as the numbers relatively to the labour force of manual and highly educated workers, respectively. The exponents in the matching function are set to be equal to half in order to simplify the welfare analysis where we derive the optimal tax and punishment system when we have imposed the traditional Hosios condition. In that case, we can disregard congestion externalities as the elasticity of the expected duration of a vacancy is equal to the bargaining power of workers in a symmetric Nash bargaining situation. ${ }^{8}$

Workers allocate search effort optimally across the formal and the informal sector. A worker with educational level $l$ will direct $\sigma_{l}^{F}$ units of search for a formal sector job and $\sigma_{l}^{I}$ units of search for an informal sector job. Thus, workers with different levels of education 
may differ in their allocation of search time across a formal and informal sector. Each worker's total search intensity is, however, exogenously given and normalized to unity, i.e. $\sigma_{l}^{F}+\sigma_{l}^{I}=1, l=m, h$. The parameter $\gamma<1$ captures the effectiveness of search falls with search effort, i.e. the first unit of search in one sector is more effective than the subsequent units of search. This could capture that different search methods are used when searching for a job in a market. The more time that is used in order to search in a market, the less efficient search methods have to be used. The transition rates into infor$\mathrm{mal}$ and formal sector employment for a particular worker $i$ are $\lambda_{l i}^{I}=\left(\sigma_{l i}^{I}\right)^{\gamma}\left(\theta_{l}^{I}\right)^{\frac{1}{2}}$ and $\lambda_{l i}^{F}=\left(1-\sigma_{l i}^{I}\right)^{\gamma}\left(\theta_{l}^{F}\right)^{\frac{1}{2}}$, where $\theta_{l}^{I}=v_{l}^{I} /\left(\left(\sigma_{l}^{I}\right)^{\gamma} u_{l}\right)$ and $\theta_{l}^{F}=v_{l}^{F} /\left(\left(1-\sigma_{l}^{I}\right)^{\gamma} u_{l}\right)$ are labour market tightness, $l=m, h$, measured in effective search units. The rates at which vacant jobs become filled are $q_{l}^{j}=\left(\theta_{l}^{j}\right)^{-\frac{1}{2}}, j=F, I, l=m, h$.

\subsection{Value functions}

Let $U_{l}, E_{l}^{F}$, and $E_{l}^{I}$ denote the expected present values of unemployment and employment for manual and highly educated workers. The value functions for worker $i$ then reads

$$
\begin{aligned}
& r U_{l i}=R+\lambda_{l i}^{F}\left(E_{l}^{F}-U_{l i}\right)+\lambda_{l i}^{I}\left(E_{l}^{I}-U_{l i}\right)-a U_{l i}, l=m, h, \\
& r E_{l i}^{F}=R+w_{l i}^{F}+s\left(U_{l}-E_{l i}^{F}\right)-a E_{l i}^{F}, l=m, h, \\
& r E_{l i}^{I}=R+w_{l i}^{I}+s\left(U_{l}-E_{l i}^{I}\right)-a E_{l i}^{I}, l=m, h,
\end{aligned}
$$

where $r$ is the exogenous discount rate, $w_{l}^{j}$ is the sector wage, and $s$ is the exogenous separation rate. $R$ is a lump sum transfer that all individuals receive from the government which reflects that the government has some positive revenue requirements. ${ }^{9}$ The parameter $a$ is the rate by which a worker is dying, and it captures that there is a constant flow of workers out of the labour market at each instant of time. Analogously, there is an equally sized flow of workers into the labour market each time period as people are born at the same rate. This keeps the population constant, normalized to unity, and enables us to look at the impact of various policies on educational attainment despite the fact that education is an irreversible investment.

Let $J_{l}^{j}$ and $V_{l}^{j} j=F, I$ represent the expected present values of an occupied job and a vacant job in the formal and informal sectors, respectively. The arbitrage equations for formal and informal sector jobs paying the wage $w_{l i}^{j} j=F, I$ and a vacant job are then

$$
\begin{aligned}
& r J_{l i}^{F}=y_{l}^{F}-w_{l i}^{F}(1+z)+s\left(V_{l}^{F}-J_{l i}^{F}\right)-a J_{l i}^{F}, l=m, h, \\
& r V_{l}^{F}=q_{l}^{F}\left(J_{l}^{F}-V_{l}^{F}\right)-k y_{l}^{F}-a V_{l}^{F}, l=m, h, \\
& r J_{l i}^{I}=y_{l}^{I}-w_{l i}^{I}\left(1+p \alpha+\kappa_{l}\right)+s\left(V_{l}^{I}-J_{l i}^{I}\right)-a J_{l i}^{I}, l=m, h, \\
& r V_{l}^{I}=q_{l}^{I}\left(J_{l}^{I}-V_{l}^{I}\right)-k y_{l}^{I}-a V_{l}^{I}, l=m, h,
\end{aligned}
$$

where $z$ is the payroll tax rate and $y_{l}^{j}, j=F, I, l=m, h$, is productivity. The parameter $p$ is the auditing rate which captures the probability of being detected employing a worker in the informal sector and $\alpha$ is the associated firm punishment fee rate. Vacancy costs are indexed by factor $k$ to the productivity in the sector and written $k y_{l}^{j}, j=F, I, l=m, h .^{10}$ 
The concealment costs, $\kappa_{l}, l=m, h$, capture that it is costly to hide income from the tax authorities. The costs could, for example, capture what Kleven et al. (2011) refer to as third-party reporting. When there is third-party reporting of income, such as the firm reporting the wage payments directly to the tax authorities, this has to be agreed upon also by the worker, which is costly. These concealment costs could also be other direct costs associated with concealing evasion, as well as morality costs associated with evading taxes.

If firms hiring highly educated workers have a harder time concealing their activities than firms hiring manual workers, then $\kappa_{h}>\kappa_{m}$. This is the case if, for example, thirdparty reporting is more common for highly educated workers, or as assumed in Kleven et al. (2011), the marginal costs of evasion increase with the amount of income evaded. Although this is likely to be the case, we do not a priori impose any restriction on the values of $\kappa_{l}, l=h, m$.

In order to improve the transparency of the model, we disregard taxation, expected punishment, and concealment costs on the worker side. This is of no importance for the results.

The unemployed worker $i$ allocates search between the two sectors, $\sigma_{l i}^{I}$, in order to maximize the value of unemployment, $r U_{l i}$. A necessary condition for an interior solution is that $\gamma<1$, which holds by assumption. The first-order condition can be written as

$$
\frac{\left(1-\sigma_{l i}^{I}\right)^{1-\gamma}}{\left(\sigma_{l i}^{I}\right)^{1-\gamma}}=\left(\frac{\theta_{l}^{F}}{\theta_{l}^{I}}\right)^{\frac{1}{2}} \frac{E_{l}^{F}-U_{l i}}{E_{l}^{I}-U_{l i}}, l=m, h .
$$

Workers allocate their search between sectors to equalize the net marginal returns to search effort across the two sectors.

\subsection{Wage determination}

When a worker and firm meet, they bargain over the wage, $w_{l i}^{j}$, taking economy-wide variables as given. The first-order conditions from the Nash bargaining with equal bargaining power for workers and firms can be written as

$$
\begin{aligned}
& J_{l}^{F}=\left(E_{l}^{F}-U_{l}\right)(1+z), l=m, h, \\
& J_{l}^{I}=\left(E_{l}^{I}-U_{l}\right)\left(1+p \alpha+\kappa_{l}\right), l=m, h,
\end{aligned}
$$

where we have imposed symmetry and the free entry condition, $V_{l}^{j}=0, j=F, I, l=$ $m, h$.

We can now derive an equation determining how search is allocated between the formal and the informal sectors in a symmetric equilibrium by substituting (9) and (10) into (8) and using $J_{l}^{F}=\frac{k y_{l}^{F}}{q_{l}^{F}}$ and $J_{l}^{I}=\frac{k y_{l}^{I}}{q_{l}^{I}}$ from (5) and (7) together with free entry. This yields

$$
\frac{\left(1-\sigma_{l}^{I}\right)^{1-\gamma}}{\left(\sigma_{l}^{I}\right)^{1-\gamma}}=\left(\frac{\theta_{l}^{F}}{\theta_{l}^{I}}\right) \frac{y_{l}^{F}}{y_{l}^{I}} \psi_{l}, l=m, h,
$$

where $\psi_{l}=\frac{1+p \alpha+\kappa_{l}}{1+z}$ is the cost wedge between the informal sector and the formal sector. When workers allocate their search between the formal and the informal sectors in equilibrium, they account for the wedge, $\psi_{l}$, and for the formal relative to the informal 
sectorial tightness, $\theta_{l}^{F} / \theta_{l}^{I}$, as well as for relative productivity, $y_{l}^{F} / y_{l}^{I}$. It follows that relatively more search will be directed towards the formal sector if expected punishment plus concealment costs are higher than the tax payments, i.e. if $\psi_{l}>1$, if formal sector tightness exceeds informal sector tightness (i.e. $\theta_{l}^{F} / \theta_{l}^{I}>1$ ), and/or if productivity in the formal sector is higher than productivity in the informal sector, $y_{l}^{F} / y_{l}^{I}>1$, and vice versa when $\psi_{l}<1, \theta_{l}^{F} / \theta_{l}^{I}<1$, and $y_{l}^{F} / y_{l}^{I}<1$. By use of Eqs. (1)-(7) and (32) in Eqs. (9) and (10), equilibrium producer wages, $\omega_{l}^{j}$, are given by

$$
\begin{aligned}
& \omega_{l}^{F}=w_{l}^{F}(1+z)=\frac{1}{2} y_{l}^{F}\left(1+k \frac{\theta_{l}^{F}}{\left(1-\sigma_{l}^{I}\right)^{1-\gamma}}\right) l=m, h, \\
& \omega_{l}^{I}=w_{l}^{I}\left(1+p \alpha+\kappa_{l}\right)=\frac{1}{2} y_{l}^{I}\left(1+\frac{\theta_{l}^{I}}{\left(\sigma_{l}^{I}\right)^{1-\gamma}} k\right), l=m, h .
\end{aligned}
$$

An increase in tightness, $\theta_{l}^{j}$, makes it easier for an unemployed worker to find a job and at the same time harder for a firm to fill a vacancy. This improves the worker's relative bargaining position, resulting in higher wage demands. An increase in search will instead increase the firm's relative bargaining position. This is the case as firms will then find it easier to match with a new worker in case of no agreement. The improved bargaining position for firms moderates wage pressure.

\subsection{Labour market tightness}

Labour market tightness for the formal sector and the informal sector are determined by Eqs. (4),(5), (6), and (7) using the free entry condition and the wage Eqs. (33) and (34):

$$
\begin{aligned}
& k(r+s+a)\left(\theta_{l}^{F}\right)^{\frac{1}{2}}=\frac{1}{2}\left(1-\frac{k \theta_{l}^{F}}{\left(1-\sigma_{l i}^{I}\right)^{1-\gamma}}\right), l=h, l, \\
& k(r+s+a)\left(\theta_{l}^{I}\right)^{\frac{1}{2}}=\frac{1}{2}\left(1-\frac{k \theta_{l}^{I}}{\left(\sigma_{l i}^{I}\right)^{1-\gamma}}\right), l=h, l .
\end{aligned}
$$

By use of the equilibrium search allocation equation in (32), where $\frac{\theta_{l}^{I}}{\left(\sigma_{l i}^{I}\right)^{1-\gamma}}=$ $\frac{\theta_{l}^{F}}{\left(1-\sigma_{l i}^{I}\right)^{1-\gamma}} \frac{y_{l}^{F}}{y_{l}^{I}} \psi_{l}$, in (15), it becomes clear that the wedge, $\psi_{l}$, and productivity differences, $y_{l}^{F} / y_{l}^{I}$, are the crucial factors determining the size of the formal sector in relation to the informal sector. ${ }^{11}$ In case productivity is the same in the formal and informal sectors, hence, $y_{l}^{F} / y_{l}^{I}=1$, then when $\psi_{l}>1$, and thus expected punishment plus concealment costs are higher than payroll taxes, informal sector producer wages are higher than formal sector producer wages. In this case, it is relatively more attractive for firms to enter the formal sector, which makes formal sector tightness exceed informal sector tightness. Hence, we obtain that $\theta_{l}^{F}>\theta_{l}^{I}$ and $\sigma_{l}^{I}<\frac{1}{2}, l=m, h$ if $\left(y_{l}^{F} / y_{l}^{I}\right) \psi_{l}>1$ and vice versa when $\left(y_{l}^{F} / y_{l}^{I}\right) \psi_{l}<1$. Notice that the formal sector exceeds the informal sector $\theta_{l}^{F}>\theta_{l}^{I}$ and $\sigma_{l}^{I}<\frac{1}{2}, l=m, h$ both if the wedge is equal to $1, \psi_{l}=1$, and the formal sector is more productive than the informal sector, $y_{l}^{F} / y_{l}^{I}>1$, as well as if the formal and informal sectors are equally productive and the wedge is larger than $1, \psi_{l}>1$.

As the formal sector exceeds the informal sector in size in most high-income countries, it is most realistic to consider the case when $\left(y_{l}^{F} / y_{l}^{I}\right) \psi_{l}>1$. This implies considering the situation when the expected punishment rate plus concealment costs exceed the tax rate, i.e. $p \alpha+\kappa_{l}>z$, when both the formal and informal sectors are equally productive, which 
does not seem unrealistic given a broad interpretation of concealment costs. In fact, as discussed in the introduction, positive concealment costs $\kappa_{l}>0$ such that $p \alpha+\kappa_{l}>z$ could potentially explain the puzzle of why we observe a relatively small informal sector although we, at the same time, observe rather low audit rates and fairly modest fines, i.e. $p \alpha<z$. In addition, when the productivity in the formal sector exceeds that of the informal sector, the formal sector is even more likely to exceed the informal sector in size. However, we do not a priori impose any restrictions on the size of $\psi_{l}, p \alpha$, or $\kappa_{l}$ when deriving the results in this paper. When discussing results that depend on the size of $\psi_{l}$, however, we focus the discussion on what we believe is the most realistic case.

In Fig. 5, we can use Eqs. (14) and (15) to derive relative tightness as a function of search intensity and illustrate this equation in a $\left(\sigma_{l}^{I}, \theta_{l}^{F} / \theta_{l}^{I}\right)$ diagram together with Eq. (11). Both equations have a negative slope, and the former curve will be flatter than the latter around the equilibrium insuring a stable equilibrium. ${ }^{12}$ When the wedge increases, $\psi_{l}^{\prime}>\psi_{l}$ (or $y_{l}^{F} / y_{l}^{I}$ increases), then the search intensity decreases for given relative labour market tightness, $\theta_{l}^{F} / \theta_{l}^{I}$; this reduction in search intensity increases $\theta_{l}^{F} / \theta_{l}^{I}$ and thereby $\sigma_{l}^{I}$ until a new equilibrium is reached. In Fig. 5, we have left out subscript $l$ to ease exposition.

\subsection{Education}

When workers decide whether to acquire higher education or remain as manual workers, they compare the value of unemployment as an educated worker and the associated costs of higher education to the value of unemployment as a manual worker. Workers that find it optimal to acquire higher education view this as a once and for all investment in human capital, and it takes place as soon as the worker enters the labour market. As in most studies, we assume that education is costly but it takes no time. ${ }^{13}$ The cost of higher education depends on individual ability, $e_{i} \in[0,1]$, and is given by $c\left(e_{i}\right)$, where $c^{\prime}\left(e_{i}\right)<0$ and $c^{\prime \prime}\left(e_{i}\right)>0 .{ }^{14}$

The marginal worker has an ability level, $\hat{e}$, which makes him or her just indifferent between acquiring higher education and remaining as a manual worker. We write the condition determining the ability level of the marginal worker as

$$
(r+a) U_{h}-c(\hat{e})=(r+a) U_{m}
$$

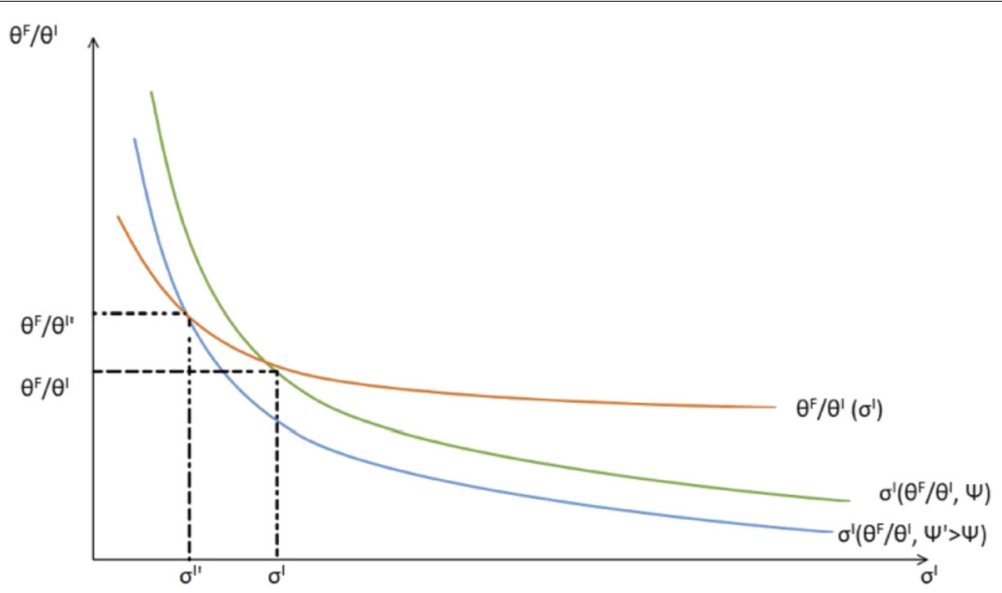

Fig. 5 Tightness in the formal sector relative to tightness in the informal sector and search intensity 
By using Eqs. (1)-(3), it is clear that workers proceed to higher education if the expected income gain of education exceeds their cost of education. However, as wages are endogenous, we can use Eqs. (1) and (16) together with the first-order conditions for wages and Eqs. (5), (7), and (11) together with the free entry condition. This gives the following rewriting of condition (16):

$$
c(\hat{e})=\frac{k}{1+z}\left(y_{h}^{F} o_{h}-y_{m}^{F} o_{m}\right),
$$

where $o_{l}=\theta_{l}^{F} /\left(1-\sigma_{l}^{I}\right)^{1-\gamma}, \quad l=h, m$. Equation (17) gives $\hat{e}$ as a function of the endogenous variables $\theta_{l}^{F}$ and $\sigma_{l}^{I}, l=m, h$. Workers with $e \leq \hat{e}$ choose not to acquire education, whereas workers with $e>\hat{e}$ acquire education. Hence, $\hat{e}$ and $1-\hat{e}$ constitute the manual and educated labour forces, respectively. The right-hand side of Eq. (17) is the expected income gain of attaining education. This gain needs to be positive in order for, at least some, workers to proceed to higher education. The fact that productivity is higher for highly educated workers, which gives rise to an educational wage premium, provides incentives for higher education. However, higher education may potentially also be associated with losses in expected income. For example, if concealment costs are higher for highly educated workers, i.e. $\kappa_{h}>\kappa_{m}$, relatively more attractive informal employment opportunities for manual workers will be foregone in case of higher education. This reduces the incentives for education. ${ }^{15}$

Clearly, in order to study the non-trivial case where at least some workers proceed to higher education, it is necessary to assume that there is a net gain in the expected income of higher education. Thus, we need to assume that productivity differences between manual and highly educated workers are sufficiently high, i.e. $y_{h}^{F} / y_{m}^{F}>o_{m} / o_{h}$. Moreover, to guarantee a non-trivial interior solution where at least some, but not all, individuals choose to acquire education, the individual with the highest ability faces a very low cost of education, more specifically $c(1)=0$, and the individual with the lowest ability faces a very high cost of education, i.e. $\lim _{e \rightarrow 0} c(e)=\infty$. See the Appendix for the proof of the existence of $\hat{e} \in(0,1)$.

\subsection{Employment and unemployment}

The equations determining the employment rates in the formal sector and the informal sector, $n_{l}^{F}, n_{l}^{I}$, and the unemployment rates, $u_{l}, l=m, h$, are given by the flow equilibrium equations and the labour force identity. ${ }^{16}$ The official unemployment rate $u_{l}^{o}$ is given by $u_{l}^{o}=u_{l}+n_{l}^{I}$. Solving for the employment and unemployment rates yields

$$
\begin{aligned}
& n_{l}^{F}=\frac{\lambda_{l}^{I}}{s+a+\lambda_{l}^{F}+\lambda_{l}^{I}}, n_{l}^{F}=\frac{\lambda_{l}^{I}}{s+a+\lambda_{l}^{F}+\lambda_{l}^{I}}, l=h, m, \\
& u_{l}=\frac{s+a}{s+a+\lambda_{l}^{F}+\lambda_{l}^{I}}, u_{l}^{o}=\frac{s+a+\lambda_{l}^{I}}{s+a+\lambda_{l}^{F}+\lambda_{l}^{I}}, l=h, m .
\end{aligned}
$$

A comparison of the unemployment rates for manual and highly educated workers requires assumptions about the size of the concealment costs. If concealment costs are higher for educated workers, i.e. $\kappa_{h}>\kappa_{m}$, the official unemployment rate is always lower for highly educated workers than for manual workers, i.e. $u_{h}^{o}<u_{m}^{o}$. This is also what is observed in data. However, if furthermore, $\left(y_{l}^{F} / y_{l}^{I}\right) \psi_{l}>1, l=h, m$, and hence the informal sector is smaller than the formal sector, the actual unemployment rate is 
higher for the highly educated workers, $u_{h}>u_{m}$, i.e. in this case, manual workers have a lower actual unemployment rate than highly educated workers. The following Proposition summarizes the results.

Proposition 1 The official unemployment rate is lower for highly educated workers, $u_{h}^{o}<u_{m}^{o}$, if they face higher concealment costs, $\kappa_{h}>\kappa_{m}$. The actual unemployment rate is higher (lower) for highly educated workers, $u_{h}>u_{m}\left(u_{h}<u_{m}\right)$, if they face higher concealment costs $\kappa_{h}>\kappa_{m}$ and these concealment costs are high (low) enough to induce $\left(y_{l}^{F} / y_{l}^{I}\right) \psi_{l}>1\left(\left(y_{l}^{F} / y_{l}^{I}\right) \psi_{l}<1\right), l=h, m$.

For proofs of all the Propositions, see the Appendix. The actual and the official total number of unemployed workers are given by

$$
\begin{gathered}
U_{\mathrm{TOT}}=\hat{e} u_{m}+(1-\hat{e}) u_{h}, \\
U_{\mathrm{TOT}}^{o}=\hat{e} u_{m}^{o}+(1-\hat{e}) u_{h}^{o} .
\end{gathered}
$$

\section{Comparative statics}

This section is concerned with the impact of more severe punishment of informal activities on labour market performance and educational attainment. We only consider fully financed changes in enforcement policies. Hence, changes in the audit rate and the punishment fees are always followed by adjustments in the tax rate so as to balance the government budget constraint given by $\hat{e} n_{m}^{F} w_{m}^{F} z+\hat{e} n_{m}^{I} w_{m}^{I} p \alpha+(1-\hat{e}) n_{h}^{F} w_{h}^{F} z+$ $(1-\hat{e}) n_{h}^{I} w_{h}^{I} p \alpha=R$. Rewriting this budget constraint in terms of producer wages using $\omega_{m}^{F}=w_{l}^{F}(1+z)$ and $\omega_{l}^{I}=w_{l}^{I}\left(1+p \alpha+\kappa_{l}\right), l=m, h$ yields

$$
\frac{z \hat{e} n_{m}^{F} w_{m}^{F}}{1+z}+\frac{p \alpha \hat{e} n_{m}^{I} w_{m}^{I}}{1+p \alpha+\kappa_{m}}+\frac{z(1-\hat{e}) n_{h}^{F} w_{h}^{F}}{1+z}+\frac{p \alpha(1-\hat{e}) n_{m}^{I} w_{h}^{I}}{1+p \alpha+\kappa_{h}}=R
$$

where $R$ is the exogenous revenue requirement.

From (40), it follows that an increase in the audit rate or the punishment fee, $p$ or $\alpha$, or an increase in the tax rate, $z$, will, for a given tax base, always increase government revenues. The tax base may, however, fall and thereby reduce revenues. If we assume that we are located on the positively sloped side of the "Laffer curves", the analysis is straightforward. Such an assumption implies that the direct effect of taxation and punishment on government revenues will always dominate the impact on revenues since the tax base may be reduced. An increase in the audit or punishment rate then always calls for a reduction in the tax rate in order to regain a balanced government budget. A fully financed increase in the punishment of the informal sector then induces $\psi_{l}$ to increase both because $p \alpha$ increases and because $z$ falls.

Although the most likely scenario is when higher punishment rates call for tax reductions in order to fulfil the government budget, the results obtained in this section for the impact of higher relative punishments of informal activities on producer wages, tightness, search, employment, and unemployment rates do not depend on this assumption. The reason is that these variables are only affected by the wedge, $\psi_{l}$, and not directly by $z$ and $p \alpha$. However, which will become clear, as educational attainment could be discouraged by a direct increase in taxation which, in turn, may have a compositional effect on total 
unemployment, the repercussions through the government budget constraint will be of importance for these variables.

To illustrate this, we discuss the potential scenario where the government revenue falls as harsher punishment of the informal sector is implemented, and the government needs to increase the tax rate in order to balance the budget. ${ }^{17}$ In this case, when there is a simultaneous increase in $z$ and $p \alpha$, there will be less sizeable adjustments in the labour market outcome variables (for example, producer wages, $\omega_{l}^{j}$, and employment rates, $n_{l}^{j}$ ) as these variables are only affected by the wedge, $\psi_{l}$, which is not altered as much when both $z$ and $p \alpha$ increase. The tax base adjustment of importance in this case is then the number of educated workers. The stock of educated workers is affected by the reform both because the wedge is altered but also directly as $z$ enters into (37) for given wedges. With the effect working through the wedge being smaller in this case, the higher tax rate is reducing the incentives to acquire higher education through the direct effect. This tax base adjustment then reduces tax revenues. However, as long as the direct impact on $R$ dominates the negative effect on the tax base through less education, the increase in $z$ will balance the government budget. This scenario will not alter the results in the labour market analysis considering the effect of more harsh punishment of the informal sector on producer wages, tightness, search, employment, and unemployment rates. The reason is, as said, that these variables are only affected by the wedge, $\psi_{l}$. The required increase in $z$ in the above considered case only implies that $\psi_{l}$ increases by less than if $z$ was reduced, and the effect on the variables will be less sizeable. In fact, even if $z$ increases to such an extent that $\psi_{l}$ actually falls, the results will hold. ${ }^{18}$ Moreover, it is of no importance for the results which side of the Laffer curves we are located on. However, the repercussions through the government budget constraint will be of importance for educational attainment and thus for the composition of unemployment.

In the budget constraint in (20), potential auditing costs are left out. To include auditing costs will not affect any of the Propositions we derive in this section. However, it affects the welfare analysis as it tends to favour costless taxation and punishment fees at the expense of auditing. The implications for the case of auditing costs is shown in the Appendix.

\subsection{Sector allocation}

Although the results of fully financed punishment of informal activities in Propositions 2 and 3 hold irrespective of how the government budget restriction is affected, to stress the intuition, we present the results based on the standard case when an increase in $p$ or $\alpha$ increases relative punishment $\psi_{l} \cdot{ }^{19}$ The effects on the allocation of search and employment across the formal and the informal sector are summarized in the following Proposition.

Proposition 2 A fully financed increase in the relative punishment of the informal sector, $\psi_{l}$, will reallocate search intensity and employment towards the formal sector, i.e. $\sigma_{l}^{I}$ falls, $n_{l}^{F}$ increases, and $n_{l}^{I}$ falls.

More zealous enforcement will make informal work less attractive, inducing unemployed workers to reallocate their search effort towards the formal sector. In addition, when search is reallocated towards the formal sector, the wage bargaining position 
strengthens for firms in the formal sector whereas it falls for firms in the informal sector. The lower producer wages in the formal sector stimulate formal firms to open vacancies, while at the same time, informal firms are discouraged to open new vacancies as they now face higher producer wages. As a consequence that both vacancies and search effort are reallocated towards the formal sector, the formal sector employment rate increases at the expense of informal employment. These mechanisms can explain the empirical findings in Almeida and Carneiro (2012) who use data on inspections carried out in Brazil.

\subsection{Unemployment rates}

As became clear in Proposition 2, employment in the formal sector increases at the expense of employment in the informal sector following more severe punishment of the informal sector. While this is somewhat expected, it is a priori not clear what would happen to the unemployment rates. We have the following results:

Proposition 3 A fully financed increase in the relative punishment of the informal sector, $\psi_{l}$, will always cause the official unemployment rate $\left(u_{l}^{o}\right)$ to fall, whereas the actual unemployment rate $\left(u_{l}\right)$ increases if $\left(y_{l}^{F} / y_{l}^{I}\right) \psi_{l}>1$ (falls if $\left(y_{l}^{F} / y_{l}^{I}\right) \psi_{l}<1$ ).

The actual unemployment rates increase with more severe punishment of informal work if $\left(y_{l}^{F} / y_{l}^{I}\right) \psi_{l}>1$. The reason for this is that the large concealment costs discourage workers from searching, and firms from opening vacancies, in the informal sector. Increased punishment of the informal sector will encourage further reallocation of search and workers away from the informal sector, where relatively efficient search methods are used, towards the formal sector. Total search efficiency then falls, inducing unemployment to increase. The fact that search becomes less efficient when reallocated towards the formal sector also has an impact on unemployment working through wage formation and tightness. As search is reallocated towards the formal sector, the wage demand is moderated in the formal sector and exaggerated in the informal sector. As the efficiency of search in the formal sector increases by less than the efficiency of search in the informal sector is reduced, the informal sector wage push will dominate the formal sector wage moderation. Thus, the incentives to open up a vacancy in the formal sector subsides the disincentives to open up a vacancy in the informal sector; the formal sector tightness will increase by less than the informal sector tightness falls when $\left(y_{l}^{F} / y_{l}^{I}\right) \psi_{l}>1$. The opposite holds if $\left(y_{l}^{F} / y_{l}^{I}\right) \psi_{l}<1$. In this case, too much search and too many firms are allocated into the informal sector as there is a relative cost advantage of producing underground. Total search efficiency would then improve when the government tries to combat the informal sector. The official unemployment rate always falls with more harsh punishment of informal activities as workers to a larger extent become formally employed. In this unemployment measure, workers in the informal sector were counted as unemployed to start with.

\subsection{Education}

From (17), it is clear that more severe relative punishment of the informal sector affects the number of educated workers as such policy increases $\psi_{l}$. This effect is further reinforced if the tax rate is reduced in order to assure a balanced government budget as the increase in $\psi_{l}$ is reinforced by a reduction in $z$. However, a reduced payroll tax rate will 
also have a direct effect on the stock of educated workers. More specifically, a reduction in the tax rate, $z$, for a given wedge, will increase the number of educated workers. This follows as taxation is more harmful to high income earners, and consequently, a tax reduction will improve the income relatively more for high income earners. However, before considering repercussions working through the budget constraint, let us first consider the impact of a more zealous enforcement policy on education, for a given tax rate. We have the following results:

Proposition 4 An increase in the audit rate, $p$, or in the punishment rate, $\alpha$, which then increases $\psi_{l}$, will increase (reduce) the number of educated workers if the relative productivity of education is in the following range $y_{h}^{F} / y_{m}^{F} \in\left[o_{m} / o_{h}, g\left(\kappa_{h}, \kappa_{m}\right) o_{m} / o_{h}\right]\left(y_{h}^{F} / y_{m}^{F} \in\right.$ $\left.g\left(\kappa_{h}, \kappa_{m}\right) o_{m} / o_{h}, \infty\right)$ where $g\left(\kappa_{h}, \kappa_{m}\right)>1$ if $\kappa_{h}>\kappa_{m}$ and $\left(y_{h}^{F} / y_{h}^{I}\right) \geq\left(y_{m}^{F} / y_{m}^{I}\right)$.

Proof. We know from above that the existence of an interior solution of $\hat{e}$ requires that $y_{h} / y_{m}>o_{m} / o_{h}$. Differentiating the educational equation with respect to expected punishment reveals that the impact on education is determined by the sign of $y_{m}\left|d o_{m} / d(p \alpha)\right|-y_{h}\left|d o_{h} / d(p \alpha)\right|$ which is equal to the sign of $y_{h}^{F} / y_{m}^{F}-g\left(\kappa_{h}, \kappa_{m}\right)\left(o_{m} / o_{h}\right)$, where the term $g\left(\kappa_{h}, \kappa_{m}\right)$ is larger than 1 for $\kappa_{h}>\kappa_{m}$ and

$$
g\left(\kappa_{h}, \kappa_{m}\right)=\frac{A_{h}\left(\frac{\theta_{h}^{F}}{\theta_{h}^{I}}\right)^{\frac{1}{1-\gamma}-\frac{1}{2}}\left(\frac{y_{h}^{F}}{y_{h}^{I}} \psi_{h}\right)^{\frac{1}{1-\gamma}}+\psi_{h}}{A_{m}\left(\frac{\theta_{m}^{F}}{\theta_{m}^{I}}\right)^{\frac{1}{1-\gamma}-\frac{1}{2}}\left(\frac{y_{m}^{F}}{y_{m}^{I}} \psi_{m}\right)^{\frac{1}{1-\gamma}}+\psi_{m}}>1 \text { for } \kappa_{h}>\kappa_{m} \text { and } \frac{y_{h}^{F}}{y_{h}^{I}} \geq \frac{y_{m}^{F}}{y_{m}^{I}},
$$

where $A_{l}=\left(1+o_{l}\right) /\left(1 / \psi_{l}+\left(y_{l}^{F} / y_{l}^{I}\right) o_{l}\right)$. See the Appendix for the full proof. Q.E.D.

The impact of a more zealous enforcement policy on educational attainment depends on how attractive underground work is to manual and educated workers. When concealment costs are higher for highly educated workers, more zealous enforcement policies tend to induce more workers to educate themselves. This follows as $\kappa_{h}>\kappa_{m}$ implies that manual workers to a larger extent face informal labour market opportunities. Therefore, more zealous enforcement policies, which make it less attractive to work in the informal sector, will be more harmful to manual workers. This effect may, however, be counteracted by the fact that highly educated workers have higher productivity and therefore earn higher wages. As also informal activities are highly productive for these workers, this implies that more harsh punishment, in this perspective, is more harmful for the highly educated worker. Thus, even if highly educated workers face less informal employment opportunities, these opportunities are more profitable. This reduces educational incentives.

Which of the two effects dominate will thus depend on how sizeable the differences in informal employment opportunities and productivity are. If underground employment opportunities in an economy foremost are available to manual workers, more harsh punishment of underground activities will push more workers into education, thus increasing the stock of educated workers in the economy. However, if these employment opportunities to a large extent also are available for highly educated workers, harder punishment will harm highly educated workers more as these opportunities are more profitable to productive workers. This leads to less workers educating themselves. 
Note that Proposition 4 only provides the sufficient conditions for when the educational stock increases and when it falls with more harsh punishment of the informal sector without considering the financing of the reform. Provided that we are located on the positively sloped side of the Laffer curve, we can conclude the following:

Proposition 5 If an increase in the audit rate, $p$, or in the punishment rate, $\alpha$, increases the number of educated workers as given by Proposition 4, the financing of the reform will further reinforce the increase in the stock of educated workers if $z$ needs to fall so as to balance the government budget.

This simply follows as taxation as a direct effect is more harmful for high income earners, and consequently, a tax reduction, in order to maintain a balanced government budget, will be more beneficial for high income earners, thus encouraging educational attainments.

\subsection{Unemployment}

From Propositions 3, 4, and 5, it follows that more severe punishment of the informal sector potentially increases the total number of unemployed workers. If the formal sector is larger than the informal sector, the unemployment rates for both manual and highly educated workers are augmented. Moreover, if informal employment opportunities to a significantly larger extent are available for manual workers, more workers will attain higher education when informal activities are punished more severely. This tends to increase total unemployment as the actual unemployment rate, including informal work, is higher for highly educated workers. Also, recall that this reallocation effect is reinforced if we are located on the positively sloped side of the Laffer curve. Thus, in this case, total unemployment increases both because the unemployment rates for all workers increase and because workers are reallocated towards the sector where the unemployment rate is highest. More generally, the Proposition summarizes the result:

Proposition 6 A fully financed increase in the audit rate, $p$, or in the punishment fee, $\alpha$, increases(decreases) the number of unemployed workers if the relative productivity of education is in the following range $\frac{y_{h}^{F}}{y_{m}^{F}} \in\left[\frac{o_{m}}{o_{h}}, g\left(\kappa_{h}, \kappa_{m}\right) \frac{o_{m}}{o_{h}}\right]$ where $g\left(\kappa_{h}, \kappa_{m}\right)>1$ if $\kappa_{h}>$ $\kappa_{m}$, where the financing of the reform further reinforces the reallocation effect if $z$ needs to fall so as to balance the government budget.

\section{Welfare}

This section is concerned with welfare analysis and the optimal design of punishment policies. As shown above, increasing the punishment fees or the audit rates affect the number of educated workers as well as the allocation of search and jobs across the formal and informal sectors. This is essential when considering the impact on welfare. For simplicity, we here let $y_{l}^{F}=y_{l}^{I}, l=h, m$.

Moreover, as the Hosios condition holds by assumption, as we have assumed that the elasticity of the expected duration of a vacancy is equal to the bargaining power of workers in a Nash bargaining situation, we can disregard congestion externalities on the labour market. Moreover, we do not need to be concerned about inefficiencies in terms of too 
low or too high educational attainments due to the holdup problem as the labour markets for workers with high and low education are separated. This enables us to focus on other, less well-known, distortions in this section. Clearly, however, if, for example, the Hosios condition does not hold, the tax and punishment policies could potentially be used to correct for congestion externalities.

The standard social welfare measure, analogous to the one described in, for example, Pissarides (2000) under no discounting, is used and can be written as

$$
\begin{aligned}
& W=\hat{e} W_{m}+\int_{\hat{e}}^{1} W_{h} d e, \\
& W_{m}=\left(1-u_{m}\right) y_{m}-u_{m} k y_{m} \Theta_{m}, \\
& W_{h}=\left(1-u_{h}\right) y_{h}-u_{h} k y_{h} \Theta_{h}-c(e),
\end{aligned}
$$

where $\Theta_{l}=\left(1-\sigma_{l}^{I}\right)^{\gamma} \theta_{l}^{F}+\left(\sigma_{l}^{I}\right)^{\gamma} \theta_{l}^{I}, l=m, h$. The welfare measure consists of aggregate production minus total vacancy costs, i.e. note that $u_{l} \Theta_{l} k=\left(v_{l}^{F}+v_{l}^{I}\right) k, l=m, h$, and minus the aggregate costs of education. With the assumption of risk neutral individuals, we ignore distributional issues, and hence, wages will not feature in the welfare function. See the Appendix for the derivation of this welfare measure.

Let us first derive the socially optimal choice of tightness, search, and stock of educated workers by maximizing the welfare function in (21)-(23) with respect to $\theta_{m}^{F}, \theta_{m}^{I}, \theta_{h}^{F}, \theta_{h}^{I}, \sigma_{m}^{I}, \sigma_{h}^{I}$, and $\hat{e}$. The socially optimal solution is solved from the following seven conditions: ${ }^{20}$

$$
\begin{aligned}
& \left(\sigma_{l}^{I *}\right)^{(\gamma-1)}-\left(1-\sigma_{l}^{I *}\right)^{\gamma-1}=0, \rightarrow \sigma_{l}^{I *}=\frac{1}{2}, l=m, h, \\
& -s k\left(\theta_{l}^{* I}\right)^{\frac{1}{2}}+\frac{1}{2}\left[1-\frac{k \theta_{l}^{* I}}{\left(\frac{1}{2}\right)^{1-\gamma}}\right]=0, l=m, h, \\
& \left(y_{h}-y_{m}\right) \frac{k \theta_{l}^{* I}}{\left(\frac{1}{2}\right)^{1-\gamma}}-c\left(\hat{e}^{*}\right)=0 .
\end{aligned}
$$

We can now compare the socially optimal solution with the market outcome. From (11), (14), and (15), it follows that the market solution for search and tightness coincides with the socially optimal allocation if the imposed tax and punishment policy are such that $\psi_{m}=\psi_{h}=1 .^{21}$

This conclusion is intuitive as any policy that induces a deviation of the $\psi_{l}, l=m, h$ from unity implies a favourable treatment of the formal or the informal sector which, in turn, induces a distortion in the sectorial allocation of search and tightness between the formal and informal sectors. For example, if search to a larger extent is allocated to the formal or informal sector instead of the other, the search is inefficiently used as less efficient search methods in that sector need to be used. Moreover, as discussed in relation to Proposition 3, a favourable treatment of either the formal or the informal sector induces too many firms to open vacancies in that sector without accounting for the externality they impose on others. In fact, unemployment is minimized when the allocation of search and tightness across the formal and informal sectors is equal, and so is vacancy costs. Thus, welfare is maximized when search and tightness are allocated equally across the formal and the informal sector. 
Now let us compare the socially optimal stock of educated workers with the educational outcome induced by the market. As the market outcome in terms of sectorial allocation of search and tightness coincided with the socially optimal one when the government lets the market face $\psi_{m}=\psi_{h}=1$, we evaluate also the private outcome of education under these conditions. This yields the following market outcome of the stock of educated workers:

$$
\left(y_{h}-y_{m}\right) \frac{k \theta_{l}^{I}}{(1+z)\left(\frac{1}{2}\right)^{1-\gamma}}-c(\hat{e})=0 .
$$

It immediately follows that a tax and punishment policy which implies that $\psi_{m}=\psi_{h}=$ 1 will not provide incentives to the market to generate a socially optimal stock of educated workers. Comparing (26) and (27), in fact, reveals that the market outcome induces too few workers to educate themselves if formal and informal sector jobs face uniform treatment in terms of $\psi_{m}=\psi_{h}=1$. This follows as taxes, captured by $(1+z)$ in (27), hit highly educated workers more severely than manual workers, which reduces the incentives of education. From this, we can conclude that welfare would increase if more workers chose to educate themselves when $\psi_{m}=\psi_{h}=1 .^{22}$

This discussion brings us to the government's explicit choice of tax and punishment policy. How should the government punish informal work in order to maximize welfare?

\subsection{Optimal punishment policy}

The welfare analysis above indicates that it may be optimal to punish tax-evading activities carried out by manual workers more severely than those carried out by highly educated workers. For example, if concealment costs are higher for highly educated workers, a punishment policy with $\psi_{m}=\psi_{h}=1$ is only possible if the manual workers to a larger extent than highly educated workers face punishment of informal activities. That is, $p \alpha$ has to be set relatively higher for manual workers if $\kappa_{m}<\kappa_{h}$ in order to induce $\psi_{m}=\psi_{h}=1$.

This raises the question of whether it is possible or not to target the punishment fees and audit rates towards the sector employing manual vs highly educated workers. While governments potentially could, and in fact do, ${ }^{23}$ target their audits to specific sectors, i.e. allowing for $p_{m}$ to differ from $p_{h}$, this is less likely the case for the fee rates.

To find the socially optimal choice of audit rates for the sector employing manual workers and the sector employing highly educated workers, the welfare function in (21)-(23) is maximized by the choice of $p_{m}$ and $p_{h}$ subject to the market reactions given by (11), (14), (15), (17), and (19) and the government budget restriction in (20). This yields the following first-order conditions:

$$
\begin{aligned}
& \frac{d W}{d p_{m}}=\hat{e} \frac{d W_{m}}{d \psi_{m}} \frac{d \psi_{m}}{d p_{m}}+\frac{d W}{d(1-e)} \frac{d(1-e)}{d p_{m}}=0, \\
& \frac{d W}{d p_{h}}=(1-\hat{e}) \frac{d W_{h}}{d \psi_{h}} \frac{d \psi_{h}}{d p_{h}}+\frac{d W}{d(1-e)} \frac{d(1-e)}{d p_{h}},
\end{aligned}
$$


where $\frac{d W_{l}}{d \psi_{l}}=\left[\sum_{j=F, I} \frac{d W_{l}}{d \theta_{l}^{j}} \frac{d \theta_{l}^{j}}{d \psi_{l}}+\frac{d W_{l}}{d \sigma_{l}^{I}} \frac{d \sigma_{l}^{I}}{d \psi_{l}}\right], j=m, h$. Evaluating the first-order conditions at the levels of $p_{m}$ and $p_{h}$ ensuring that $\psi_{m}=\psi_{h}=1$ turns out to be very convenient and gives

$$
\begin{aligned}
& \left.\frac{d W}{d p_{m}}\right|_{\psi_{m}=1}=\frac{d W}{d(1-\hat{e})} \frac{d(1-\hat{e})}{d p_{m}}>0, \\
& \left.\frac{d W}{d p_{h}}\right|_{\psi_{h}=1}=\frac{d W}{d(1-\hat{e})} \frac{d(1-\hat{e})}{d p_{h}}<0 .
\end{aligned}
$$

Provided that we are located on the positively sloped side of the Laffer curves, we can conclude that

Proposition 7 Welfare is maximized when the sector employing manual workers is audited to a larger extent than the sector employing highly educated workers, i.e. $p_{m}>p_{h}$ so as to get $\psi_{h}^{*}<1<\psi_{m}^{*}$ if $\kappa_{h} \geq \kappa_{m}$.

Proof. Evaluate the first-order conditions (28) and (29) at $\psi_{m}=\psi_{h}=1$. From the socially optimal allocation of search and tightness, $\psi_{l}=1 \mathrm{implies}$ that $\frac{d W_{l}}{d \theta_{l}^{F}}=\frac{d W_{l}}{d \theta_{l}^{I}}=$ $\frac{d W_{l}}{d \sigma_{l}^{I}}=0, l=m, h$. Then $\left.\frac{d W}{d p_{m}}\right|_{\psi_{m}=1}=\frac{d W}{d(1-e)} \frac{d(1-e)}{d p_{m}}>0$ and $\left.\frac{d W}{d p_{h}}\right|_{\psi_{h}=1}=\frac{d W}{d(1-e)} \frac{d(1-e)}{d p_{h}}<0$ as $\frac{d W}{d(1-e)}>0$ from (26) and (27) and $\frac{d(1-\hat{e})}{d p_{m}}>0, \frac{d(1-\hat{e})}{d p_{h}}<0$ from (17). Thus, welfare improves by reallocation of audits towards the manual sector. If $\kappa_{h}=\kappa_{m}, p_{m}=p_{h}$ at $\psi_{m}=\psi_{h}=1$, welfare improves by setting $p_{m}>p_{h}$. If $\kappa_{h}>\kappa_{m}$, the results are reinforced as $p_{m}>p_{h}$ already when $\psi_{m}=\psi_{h}=1$, and welfare improves by further increasing $p_{m}$ and reducing $p_{h}$. Q.E.D.

The result in Proposition 7 follows straightforwardly from the first-order conditions when evaluated at the $p_{m}$ and $p_{h}$ which induces $\psi_{m}=\psi_{h}=1$. The first term on the righthand side of Eqs. (28) and (29) then disappears as the distortions in search and allocation of tightness across the formal and the informal sector are fully eliminated. In this case, there are no other distortions present except that too few workers have chosen to educate themselves. Recall that this is a consequence that taxation harms high income earners relatively more. This distortion can, however, be corrected for by increasing the audits in the manual sector and reducing them in the sector for highly educated workers, which is captured by the right-hand side in (30) and (31). As informal sector work for manual workers becomes less attractive when the government increases the number of audits, manual workers are encouraged to acquire higher education. Similarly, less audits in the highly educated sector further encourages workers to acquire higher education.

If concealment costs are higher in the sector employing highly educated workers, i.e. $\kappa_{h}>\kappa_{m}$, there are even further incentives for the government to focus their audits on the manual sector. This follows as high concealment costs work as a self-regulating punishment of informal sector activities. Thus, if concealment costs are higher in the sector employing highly educated workers, this sector will be in less need of audits as concealment costs will do part of the job of limiting the size of the informal sector.

Moreover it follows that 
Corollary 8 The stock of educated workers is below its socially optimal value when the audit rates are chosen so as to maximize welfare.

Proof. See the Appendix.

When deciding on the optimal audit rates, the government faces a trade-off between two distortions and it is never optimal to fully eliminate one of them. When the stock of educated workers is at its socially optimal level, there is an inefficient allocation of search and jobs across the formal and informal sectors. Welfare then improves as the stock of educated workers is reduced below its socially optimal level as this will only be a secondorder effect in comparison to the improved welfare following a more efficient sectorial allocation.

\subsection{Optimal punishment policy when concealment costs are high}

In deriving the optimal audit rates in the previous section, it was implicitly assumed that audit rates could be chosen freely without restrictions. For example, according to Proposition 7 , the audit rates should be chosen such that $p_{m}^{*}>p_{h}^{*}$ so as to get $\psi_{h}^{*}<1<\psi_{m}^{*}$. However, this is only possible if concealment costs are not too high. If, for example, $\kappa_{h}>z$, then $\psi_{h}>1$ even when $p_{h}$ is very small. Replacing the first-order condition in (29) with the appropriate Kuhn-Tucker conditions, $\frac{d W}{d p_{h}}+\mu=0, p_{h} \geq 0$, and $\mu p_{h}=0$, where $\mu$ is the Lagrange multiplier for the constraint $p_{h} \geq 0$, then suggests that the audit rate in the sector should be set as low as possible when $\kappa_{h}>z$. Concealment costs are simply high enough to self-regulate the size of the informal sector facing highly educated workers, and there is no need for additional audits of this sector. ${ }^{24}$

Taking off in real-world observations from high-income economies, this may not be an unrealistic scenario. Evidence indicates that manual workers, or workers with a lower level of formal education, to a substantially larger degree face informal employment opportunities compared to highly educated workers. Pedersen and Smith (1998) using comprehensive survey data find that almost half of the informal sector activities in Denmark is carried out within the construction sector. They also find that around $70 \%$ of the total hours performed in the informal sector is carried out within the service sector or construction sector.

Potential explanations for why manual, in contrast to highly educated, workers engage in informal activities are that manual workers to a larger extent work in industries which handle cash payments or are to a lesser extent subject to third-party reporting. Firms and workers in industries dealing with cash payments, or which to a lesser extent are subject to third-party reporting, will find it easier, and thus less costly, to conceal their tax evasion. Taking this at face value implies that concealment costs for highly educated workers, $\kappa_{h}$, could be very large. If $\kappa_{h}$ is assumed to approach infinity, informal employment opportunities facing highly educated workers will become infinitely small, leading to that basically no firms will post informal sector vacancies to highly educated workers and none of the highly educated workers will allocate search effort into the informal sector. All the results derived in Propositions 1 to 6 account for this special case, including the now clear-cut result that higher punishment fees, or a general increase in the audit rate, encourage more workers to educate themselves. This follows as less workers will remain as manual workers as the foregone informal employment opportunities when attaining 
education has become less attractive. Moreover, the socially optimal audit rate is again being determined by an audit rate which implies that $p_{m}^{*}$ is set large enough so as to get $\psi_{m}^{*}>1$, although not high enough to induce an efficient stock of educated workers.

\subsection{Multiple equilibria}

Again, consider the case when the government can target the audits towards the sectors for manual and highly educated workers. That $\psi_{l}=\left(1+p_{l} \alpha+\kappa_{l}\right) /(1+z)$ can be obtained both through high tax and enforcement rates and through low tax and enforcement rates raises the issue of multiple equilibria. ${ }^{25}$ The relationship between the punishment rates and the tax rate in each sector can then be written as $p_{l} \alpha=\bar{\psi}_{l}(1+z)-\left(1+\kappa_{l}\right)$ where the wedge in each sector is set to some fixed value $\bar{\psi}_{l}$. A 1 -unit increase in $z$ followed by an increase in $p_{l} \alpha$ by $\bar{\psi}_{l}$ units maintains the relative punishment rate given by $\bar{\psi}_{l}$.

From the government budget constraint in (20), it is clear that any revenue requirement could then be reaped through such simultaneous increases in $z$ and $p_{l} \alpha$, if it was not for adjustments in the stock of educated workers. This follows as the tax base in terms of producer wages, $\omega_{l}^{j}$, and employment rates, $n_{l}^{j}$, only depends on $\psi_{l}$ whereas education falls with higher taxes for given wedges. The fact that the tax base falls with higher taxation through reduced incentives for education opens up for the possibility of two equilibria where the government can collect the same revenue although at different levels of tax and enforcement rates.

In the high tax and enforcement economy, very few workers may choose to educate themselves which reduces the tax base and thus induces modest tax revenues even though tax rates are high (negatively sloped side of the Laffer curve). In the low tax and enforcement economy, in contrast, many workers find it worthwhile to educate themselves which induces a large tax base which enables the government to obtain equally high revenues despite low tax rates (positively sloped side of the Laffer curve). This scenario is potentially possible in our model.

The scenario is shown graphically in Fig. 6 in terms of a Laffer curve with tax revenues, $R$, on the vertical axis whereas the horizontal axis captures the tax rate, $z$, for given wedges, $\bar{\psi}_{l}$. As the only tax base adjustment taking place is with regard to education, the direct effect is fairly strong indicating that revenues always tend to increase with $z$ (the filled curve). However, the direct effect becomes less strong as taxation becomes heavier because there are fewer highly educated workers to tax. On the other hand, the response in terms of the number of workers acquiring higher education is stronger when $z$ is low. This is captured by the convex cost function for education. Including auditing costs into the government budget constraint clearly tends to increase the likelihood of being in a situation where an increase in tax rate, and increases in $p_{l} \alpha$ so as to keep $\bar{\psi}_{l}$ constant, no longer increases government revenues, thus also increasing the likelihood of multiple equilibria (dotted line in Fig. 6).

In the case of two equilibria, the low tax and enforcement equilibria is preferable from a welfare point of view. As was seen in Section 5.1, it was optimal to correct for the distortion in terms of that too few workers did choose to educate themselves. However, it was not optimal to fully correct for this distortion, leaving the educated stock below a socially optimal value, since distortions on the labour market then became inefficiently high. Clearly, the high tax and enforcement economy worsens the problem by inducing an educational stock which is, for the same wedge, even further away from what is socially 


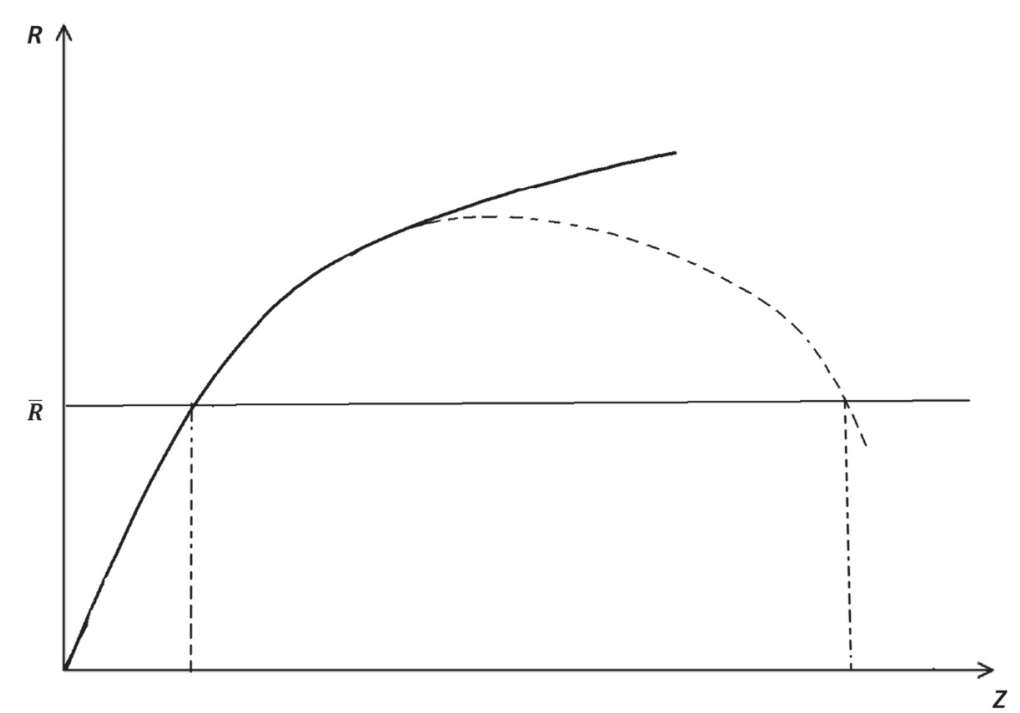

Fig. 6 The Laffer curve; revenue $R$ as a function of payroll taxes, $z$

optimal. This leads the government to use the wedges to push the economy further away from an efficient labour market outcome in order to correct for this additional distortion in education. Both the labour market distortions and the educational distortion is in this economy larger at the socially optimal wedges than at the socially optimal wedges chosen under the low tax and enforcement economy.

\section{Conclusions}

There has recently been an intensified focus on issues related to tax evasion and informal activities from both a policy and research perspective. ${ }^{26}$ The study by Kleven et al. (2011), which conducted a large field experiment in Denmark, made it possible to address, and convincingly answer, a number of questions related to tax compliance behaviour that had not been answered before.

This paper uses this knowledge to investigate the general equilibrium implications of informal sector activities on economic performance. A number of questions can be asked. How will informal employment opportunities affect labour market performance and educational attainments? Can informal jobs really be turned into formal jobs by more zealous punishment policies? And if so, to what extent will formal sector jobs replace jobs in the informal sector?

In order to address these questions, we develop a four-sector equilibrium search and matching model with informal sector employment opportunities and educational choice. We find that informal activities reduce the incentives to acquire higher education if informal employment opportunities mainly are available to low-educated workers. More zealous enforcement policies will in this case improve educational incentives as it reduces the attractiveness of remaining a low-educated worker. Moreover, we find that stricter enforcement policies will create new jobs in the formal sector, although most likely to a lesser extent than the number of jobs destructed in the informal sector. This will lead to an increase in the actual unemployment rates although the official unemployment rates fall. Finally, characterizing the optimal enforcement 
policies, we find that relatively more audits should be targeted towards the sector employing low-educated workers; elsewise, a too low stock of educated workers could materialize.

Including unemployment insurance and that a successful audit implies a termination of a match are possible extensions which are on our agenda for future research.

\section{Endnotes}

${ }^{1}$ A number of studies have studied various implications of education in search and matching models. See, for example, Acemoglu (1996) and Charlot et al. (2005).

${ }^{2}$ Productivity differences between formal and informal work are usually considered to be very important in the literature on informality in low- and middle-income countries. See La Porta and Shleifer (2014).

${ }^{3}$ Note that this literature considers, as do we, workers and firms that either fully operate in the informal sector or not, rather than partially doing so. The traditional literature on tax evasion, in contrast, focused mainly on under-reporting of income. See Allingham and Sandmo for a seminal paper on tax evasion where under-reporting of income is modelled as a decision made under uncertainty. Thus, tax evasion can be seen both as an intensive margin decision and as an extensive margin decision, where our focus is on the latter.

${ }^{4}$ See also Bosch and Esteban-Pretel (2012) for a model based on a similar set-up calibrated by use of flow data from Brazil.

${ }^{5}$ More specifically, they a use a Multiple Indicators Multiple Causes (MIMIC) model to analyse and estimate the size of the informal sector of 162 countries around the world. They define the sector as given by all market-based legal production of goods and services that are deliberately concealed from public authorities either to avoid payment of taxes or social security contributions or to avoid meeting certain legal labour market standards or avoid complying with certain administrative procedures. Thus, the definition does not include crimes like burglary, robbery, and drug dealing.

${ }^{6}$ The availability and accessibility of information to authorities on jurisdictional ownership, accounting records, and banking, are divided into five categories according to if the standards are "in place", "in place but there is need for improvements", and "not in place". The index is constructed as the proportion of the five categories that are in place. Thus, the index takes on values between 0 and 1 , where index value 1 is given to countries that have all the standards in place.

${ }^{7}$ A country with relaxed regulations against tax evasion does not automatically make it attractive to work in the informal sector or the opposite if the regulation is strict. If taxes are very low, the strictness of the regulation against tax evasion becomes less relevant for tax evasion.

${ }^{8}$ Problems with holdups can appear if workers make their educational investment prior knowing what type of employer they will meet, as for firms making their investments in physical capital prior knowing what type of worker they will meet, as they pay the full cost of the investment but only reap part of its benefits. As firms may meet a loweducated worker, they have lower incentives to invest in capital, and as workers may meet a firm with low capital, they have lower incentives to invest in human capital. This tends to induce underinvestments in both physical and human capital from a social point of view. This problem is, however, ruled out in our paper as educated workers direct their 
search towards jobs exclusively for educated workers (see Acemoglu 1996; Acemoglu and Shimer 1999).

${ }^{9}$ Everyone receives the transfer $R$. The government cannot exclude the informal sector workers as the government does not know who the informal sector workers are (if it did, it could punish all of them). We disregard unemployment insurance as these will complicate the model significantly and in order to keep the formal and informal sectors as symmetric as possible. In the presence of unemployment insurance, informal sector workers will also receive unemployment insurance. As formal sector workers do not receive unemployment insurance, this will tend to raise formal sector wages but will have no direct impact on informal sector wages. Therefore, unemployment insurance will tend to reduce the supply of formal sector jobs relatively to informal sector jobs.

${ }^{10}$ It is natural to think that $\alpha \geq z$ as the punishment fee should at least cover the evaded taxes.

${ }^{11}$ When $y_{l}^{F} / y_{l}^{I}=1$, relative tightness is determined by $\theta_{l}^{F} / \theta_{l}^{I}=\left(\frac{1-k \theta_{l}^{F}\left(1-\sigma_{l}\right)^{\gamma-1}}{1-k \theta_{l}^{F}\left(1-\sigma_{l}\right)^{\gamma-1} \psi_{l}}\right)^{2} \gtreqless$ 1 if $\psi_{l} \gtreqless 1$.

${ }^{12}$ An appendix with the equations and derivations is available upon request.

${ }^{13}$ See Charlot et al. (2005) for a study that investigates the educational decision in a search and matching framework when education is time consuming.

${ }^{14}$ The costs of education can capture a number of things, for example, direct costs of education such as tuition fees. Workers with high ability may face lower costs of this type due to, for example, scholarships. Also, such direct costs of education can be managed by student loans in a time when the worker has no funds and just entered the labour market. Workers need to pay these loans back, with interest, also in many periods after the education has ended. Thus, although the educational attainment is a once and for all investment, the cost of the education can be paid in future periods. The results on how punishment policies affect labour market and educational outcomes will not change if we let $c(e)=(r+a) \tilde{c}(e)$ where $r+a$ is the overall interest rate and $\tilde{c}(e)$ is the cost of attaining the education. The costs of education can also capture the indirect cost, such as effort costs, of being a highly educated worker.

${ }^{15}$ See the Appendix for the proof that $o_{h}<o_{m}$ when $\kappa_{h}>\kappa_{m}$.

${ }^{16}$ For highly educated workers, $\lambda_{h}^{F} u_{h}(1-\hat{e})=(s+a) n_{h}^{F}(1-\hat{e}), \lambda_{h}^{I} u_{h} \hat{e}=(s+a) n_{h}^{I}$ $(1-\hat{e})$ and $n_{h}^{F}+n_{h}^{I}=1-u_{h}$, and for manual workers, $\lambda_{m}^{F} u_{m} \hat{e}=(s+a) n_{m}^{F} \hat{e}, \lambda_{m}^{I} u_{m} \hat{e}=$ $(s+a) n_{m}^{I} \hat{e}$, and $n_{m}^{F}+n_{m}^{I}=1-u_{m}$.

${ }^{17}$ This could, for example, be the case if we have auditing costs in the government budget constraint. It is often assumed that taxes and punishment fees are cheap government instruments whereas audits are costly to carry out.

${ }^{18}$ Let us provide an illustration of the rather peculiar case when $z$ increases to such extent that $\psi_{l}$ actually falls with the reform. In this case, an increase in the relative punishment of the informal sector instead takes place through a reduction in the informal punishment which increases the government revenues. This in turn enables a reduction in $z$ which, in this special case, is large enough to increase $\psi_{l}$. And through the large reduction in $z$, the punishment of the informal sector has increased relative to the taxation of the formal sector as taxation has fallen significantly. Although the results in the analysis of the impact of fully financed punishment of informal activities on producer wages, search, tightness, unemployment, and employment rates holds irrespective 
of how the government budget restriction is affected, to stress the intuition, we present the results in terms of the standard scenario in the paper.

${ }^{19}$ That is, the corresponding adjustment in $z$ in order to regain a balanced budget implies that $z$ either falls or does not increase to such an extent inducing $\psi_{l}$ to fall. See the footnote for this special case.

${ }^{20}$ See the Appendix for the second-order conditions.

${ }^{21}$ When $\psi_{m}=\psi_{h}=1$ is imposed on the private solution, it follows from (14) and (15) that tightness in the formal and the informal sector is equal and that search must be split equally between the formal and the informal sector, i.e. $\sigma^{I}=\frac{1}{2}$ from (11). Imposing $\sigma^{I}=\frac{1}{2}$ and $\theta_{l}^{F}=\theta_{l}^{I}, l=m, h$, under the assumption of no discounting, in (14) and (15), yields the same expression as (25).

${ }^{22}$ There may, of course, be other more direct instruments if the pure aim is to correct for inefficiencies in the educational level in an economy, but nevertheless, it should be acknowledged that the wedge actually has an impact on the number of educated workers and thereby potentially has an impact on welfare in the economy.

${ }^{23}$ See, for example, Kleven et al. (2011).

${ }^{24}$ This clearly holds also for the manual sector if concealment costs are higher than the tax rate.

${ }^{25}$ The general principal in this section holds also when the government cannot target the audits. It is then not possible for the government to increase the tax rate holding both wedges constant through adjustments in $p_{l} \alpha$ as $\kappa_{l}$ differs across the sectors. The government would then increase $p \alpha$ so that the wedges marginally change. There would then be marginal adjustments in the producer wages and employment rates.

${ }^{26}$ The OECD recently initiated the "Global forum of transparency and exchange of information for tax purposes" (OECD 2012), whereas the European commission conducted the first EU-wide comparable questionnaire in order to increase the knowledge about tax evasion in Europe (see EC (2007)).

\section{Appendix}

The model is given by

$$
\frac{\left(1-\sigma_{l}^{I}\right)^{1-\gamma}}{\left(\sigma_{l}^{I}\right)^{1-\gamma}}=\left(\frac{\theta_{l}^{F}}{\theta_{l}^{I}}\right) \frac{y_{l}^{F}}{y_{l}^{I}} \psi_{l}, l=m, h .
$$

where $\psi_{l}=\frac{1+p \alpha+\kappa_{l}}{1+z}$

$$
\begin{aligned}
& \omega_{l}^{F}=w_{l}^{F}(1+z),=\frac{1}{2} y_{l}^{F}\left(1+k \frac{\theta_{l}^{F}}{\left(1-\sigma_{l}^{I}\right)^{1-\gamma}}\right) l=m, h, \\
& \omega_{l}^{I}=w_{l}^{I}\left(1+p \alpha+\kappa_{l}\right)=\frac{1}{2} y_{l}^{I}\left(1+\frac{\theta_{l}^{I}}{\left(\sigma_{l}^{I}\right)^{1-\gamma}} k\right), l=m, h, \\
& k(r+s+a)\left(\theta_{l}^{F}\right)^{\frac{1}{2}}=\frac{1}{2}\left(1-\frac{k \theta_{l}^{F}}{\left(1-\sigma_{l}^{I}\right)^{1-\gamma}}\right), m=h, l, \\
& k(r+s+a)\left(\theta_{l}^{I}\right)^{\frac{1}{2}}=\frac{1}{2}\left(1-\frac{k \theta_{l}^{I}}{\left(\sigma_{l}^{I}\right)^{1-\gamma}}\right), m=h, l .
\end{aligned}
$$


Educational choice

$$
c(\hat{e})=\frac{k}{1+z}\left(y_{h}^{F} o_{h}-y_{m}^{F} o_{m}\right)
$$

Employment and unemployment

$$
\begin{aligned}
& n_{l}^{F}=\frac{\lambda_{l}^{I}}{s+a+\lambda_{l}^{F}+\lambda_{l}^{I}}, n_{l}^{F}=\frac{\lambda_{l}^{I}}{s+a+\lambda_{l}^{F}+\lambda_{l}^{I}}, l=h, m, \\
& u_{l}=\frac{s+a}{s+a+\lambda_{l}^{F}+\lambda_{l}^{I}}, u_{l}^{o}=\frac{s+a+\lambda_{l}^{I}}{s+a+\lambda_{l}^{F}+\lambda_{l}^{I}}, l=h, m .
\end{aligned}
$$

Budget constraint in terms of producer wages using $\omega_{m}^{F}=w_{l}^{F}(1+z)$ and $\omega_{l}^{I}=w_{l}^{I}(1+$ $\left.p \alpha+\kappa_{l}\right), l=m, h$, yields

$$
\frac{z \hat{e} n_{m}^{F} w_{m}^{F}}{1+z}+\frac{p \alpha \hat{e} n_{m}^{I} w_{m}^{I}}{1+p \alpha+\kappa_{m}}+\frac{z(1-\hat{e}) n_{h}^{F} w_{h}^{F}}{1+z}+\frac{p \alpha(1-\hat{e}) n_{m}^{I} w_{h}^{I}}{1+p \alpha+\kappa_{h}}=R
$$

where $R$ is the exogenous revenue requirement.

\section{Tightness relatively to search intensity}

We show that $\frac{\theta_{t}^{F}}{\left(1-\sigma_{t}^{I}\right)^{1-\gamma}}<\frac{\theta_{x}^{F}}{\left(1-\sigma_{x}^{I}\right)^{1-\gamma}}$ when $\kappa_{t}>\kappa_{x}$ in the following way. Differentiating equations (35), (36), and (32) with respect to $\kappa_{l}$ gives around the equilibrium

$$
\begin{aligned}
& \frac{d \theta_{l}^{F}}{d \kappa_{l}}=\frac{\frac{(1-\gamma)}{1-\sigma_{l}^{I}} \frac{k \theta_{l}^{F}}{\left(1-\sigma_{l}^{I}\right)^{1-\gamma}} \frac{1}{2}\left(1+\frac{k \theta_{l}^{F}}{\left(\sigma_{l}^{I}\right)^{1-\gamma}}\right) \frac{1}{\theta_{l}^{I}}}{D_{l}}\left(1+p \alpha+\kappa_{l}\right)>0, \\
& \frac{d \theta_{l}^{I}}{d \kappa_{l}}=-\frac{\frac{1}{2}\left(1+\frac{k \theta_{l}^{F}}{\left(1-\sigma_{l}^{I}\right)^{1-\gamma}}\right) \frac{1}{\theta_{l}^{F}}(1-\gamma) k \theta_{l}^{I}\left(\sigma_{l}^{I}\right)^{\gamma-2}}{D_{l}}\left(1+p \alpha+\kappa_{l}\right)<0, \\
& \frac{d \sigma_{l}^{I}}{d \kappa_{l}}=-\frac{\frac{1}{2}\left(1+\frac{k \theta_{l}^{F}}{\left(1-\sigma_{l}^{I}\right)^{1-\gamma}}\right) \frac{1}{\theta_{l}^{F}} \frac{1}{2}\left(1+\frac{k \theta^{I}}{\left(\sigma_{l}^{I}\right)^{1-\gamma}}\right) \frac{1}{\theta_{l}^{I}}}{D_{l}}\left(1+p \alpha+\kappa_{l}\right)<0,
\end{aligned}
$$

where

$$
\begin{aligned}
D_{l}= & \frac{(1-\gamma) \frac{1}{\sigma_{l}^{I}}}{\theta_{l}^{I} \theta_{l}^{F} 4\left(1-\sigma_{l}^{I}\right)}\left(\frac{\frac{1}{\left(y_{l}^{F} / y_{l}^{I}\right) \psi_{l}} k \theta_{l}^{I}}{\left(\sigma_{l}^{I}\right)^{1-\gamma}}+1\right)\left(1-\frac{k \theta^{I}}{\left(\sigma_{l}^{I}\right)^{1-\gamma}}\right)\left(1-\sigma_{l}^{I}\right) \\
& +\left(\frac{k \theta_{l}^{I}}{\left(\sigma_{l}^{I}\right)^{1-\gamma}}+1\right)\left(1-\frac{\frac{1}{\left(y_{l}^{F} / y_{l}^{I}\right) \psi_{l}} k \theta^{I}}{\left(\sigma_{l}^{I}\right)^{1-\gamma}}\right)
\end{aligned}
$$

Now, differentiating $\frac{\theta_{l}^{F}}{\left(1-\sigma_{l}^{I}\right)^{1-\gamma}}$ with respect to $\kappa_{l}$ gives

$$
\begin{aligned}
& \frac{d \frac{\theta_{l}^{F}}{\left(1-\sigma_{l}\right)^{1-\gamma}}}{d \kappa_{l}}=\frac{d \theta_{l}^{F}\left(1-\sigma_{l}\right)^{\gamma-1}}{d \kappa_{l}}=\theta_{l}^{F}\left(1-\sigma_{l}\right)^{\gamma-1}\left(\left(\theta^{F}\right)^{-1} \frac{d \theta_{l}^{F}}{d \kappa_{l}}+(1-\gamma)\left(1-\sigma_{l}\right)^{-1} \frac{d \sigma^{I}}{d \kappa_{l}}\right)= \\
& =-\frac{\theta_{l}^{F}\left(1-\sigma_{l}\right)^{\gamma-1}}{4 D_{l}} \frac{(1-\gamma)}{\left(1-\sigma_{l}^{I}\right)}\left(1+\frac{k \theta_{l}^{I}}{\left(\sigma_{l}^{I}\right)^{1-\gamma}}\right) \frac{1}{\theta_{l}^{F} \theta_{l}^{I}}\left(1-\frac{k \theta_{l}^{F}}{\left(1-\sigma_{l}^{I}\right)^{1-\gamma}}\right)\left(1+p \alpha+\kappa_{l}\right)<0 .
\end{aligned}
$$

Hence, if $\kappa_{t}>\kappa_{x}$, then $\frac{\theta_{t}^{F}}{\left(1-\sigma_{t}\right)^{1-\gamma}}<\frac{\theta_{x}^{F}}{\left(1-\sigma_{x}\right)^{1-\gamma}}$. 


\section{Existence of $\hat{e} \in(0,1)$}

Consider the educational Eq. (37). For a non-trivial solution, there needs to be a net gain in expected income of higher education. Thus, $y_{h}^{F} / y_{m}^{F}>o_{m} / o_{h}$. Moreover, to guarantee a non-trivial interior solution where at least some, but not all, individuals choose to acquire education, the individual with the highest ability faces a very low cost of education, more specifically $c(1)=0$, and the individual with the lowest ability faces a very high cost of education, i.e. $\lim _{e \rightarrow 0} c(e)=\infty$.

In the case $\kappa_{h} \leq \kappa_{m}$, then $o_{m} / o_{h}<1$, and hence, $y_{h}^{F} / y_{m}^{F}>o_{m} / o_{h}$ holds as $y_{h}^{F}>y_{m}^{F}$. If educated workers face higher concealment costs than manual workers $\kappa_{h}>\kappa_{m}$, then we need to assume that the productivity gain of education is large enough to assure that $y_{h}^{F} / y_{m}^{F}>o_{m} / o_{h}$ holds, which is possible as the right-hand side is independent of $y_{l}$.

\section{Relative unemployment rates (Proposition 1)}

Unemployment is increasing in concealment costs if $\psi_{l}>1$. Hence, if $\kappa_{t}>\kappa_{x}$, then $u_{t}>u_{x}$ if $\psi_{l}>1$. We show that in the following way, $u_{t}>u_{x}$ if and only if $s /\left(s+\lambda_{x}^{F}+\lambda_{x}^{I}\right)<s /\left(s+\lambda_{t}^{F}+\lambda_{t}^{I}\right)$ if an only if $\lambda_{t}^{F}+\lambda_{t}^{I}<\lambda_{x}^{F}+\lambda_{x}^{I}$. Hence, the condition holds if

$$
\begin{aligned}
& \frac{d\left(\lambda_{l}^{F}+\lambda_{l}^{I}\right)}{d \kappa_{l}}=\frac{d\left[\left(1-\sigma_{l}^{I}\right)^{\gamma}\left(\theta_{h}^{F}\right)^{\frac{1}{2}}+\left(\sigma_{l}^{I}\right)^{\gamma}\left(\theta_{h}^{I}\right)^{\frac{1}{2}}\right]}{d \kappa_{l}} \\
& =\gamma\left(-\left(1-\sigma_{l}^{I}\right)^{\gamma-1}\left(\theta_{l}^{F}\right)^{\frac{1}{2}}+\left(\sigma_{l}^{I}\right)^{\gamma-1}\left(\theta_{l}^{I}\right)^{\frac{1}{2}}\right) \frac{d \sigma_{l}^{I}}{d \kappa_{l}}+\frac{1}{2}\left(\frac{\left(1-\sigma^{I}\right)^{\gamma}}{\left(\theta_{l}^{F}\right)^{\frac{1}{2}}} \frac{d \theta_{l}^{F}}{d \kappa_{l}}+\frac{\left(\sigma^{I}\right)^{\gamma}}{\left(\theta_{l}^{I}\right)^{\frac{1}{2}}} \frac{d \theta_{l}^{I}}{d \kappa_{l}}\right)<0 .
\end{aligned}
$$

We substitute for the derivatives and the first-order condition for search intensity to obtain the condition equal to

$$
\begin{aligned}
& =\gamma\left(\frac{1}{\psi_{l} \frac{y_{l}^{F}}{y_{l}^{I}}\left(\theta_{l}^{F}\right)^{\frac{1}{2}}}-\frac{1}{\left(\theta_{l}^{I}\right)^{\frac{1}{2}}}\right)\left(1+\frac{k \theta_{l}^{I}}{\frac{y_{l}^{F}}{y_{l}^{I}} \psi_{l}\left(\sigma_{l i}^{I}\right)^{1-\gamma}}\right)\left(1+\frac{k \theta_{l}^{I}}{\left(\sigma_{l i}^{I}\right)^{1-\gamma}}\right) \\
& +(1-\gamma) \frac{k \theta_{l}^{I}}{\left(\sigma_{l i}^{I}\right)^{1-\gamma}}\left(\frac{1}{\left(\theta_{l}^{F}\right)^{\frac{1}{2}}} \frac{1}{\frac{y_{l}^{F}}{y_{l}^{I}} \psi_{l}}\left(\frac{1}{\frac{y_{l}^{F}}{y_{l}^{I}} \psi_{l}}+\frac{k \theta_{l}^{I}}{\frac{y_{l}^{F}}{y_{l}^{I}} \psi_{l}\left(\sigma_{l i}^{I}\right)^{1-\gamma}}\right)-\frac{1}{\left(\theta_{l}^{I}\right)^{\frac{1}{2}}}\left(1+\frac{k \theta_{l}^{I}}{\frac{y_{l}^{F}}{y_{l}^{I}} \psi_{l}\left(\sigma_{l i}^{I}\right)^{1-\gamma}}\right)\right)
\end{aligned}
$$

which is negative when $y^{F} / y^{F} \geq 1$ and $\psi_{l}>1$, as then $\theta_{l}^{F}>\theta_{l}^{I}$ giving $\frac{1}{\frac{y_{l}^{F}}{y_{l}^{I}} \psi_{l}} \frac{1}{\left(\theta_{l}^{F}\right)^{\frac{1}{2}}}<\frac{1}{\left(\theta_{l}^{I}\right)^{\frac{1}{2}}}$ and $\left(\frac{1}{\frac{y_{l}^{F}}{y_{l}^{I}} \psi_{l}}+\frac{1}{\frac{y_{l}^{F}}{y_{l}^{I}} \psi_{l}} \frac{k \theta^{I}}{\left(\sigma_{l}^{I}\right)^{1-\gamma}}\right)<\left(1+\frac{1}{\frac{y_{l}^{F}}{y_{l}^{I}} \psi_{l}} \frac{k \theta^{I}}{\left(\sigma_{l}^{I}\right)^{1-\gamma}}\right)$. Hence, unemployment increases with $\psi_{l}$, and hence, $u_{t}>u_{x}$ when $y_{h}^{F} / y_{l}^{I} \geq 1$ and $\kappa_{t}>\kappa_{x}$.

The official unemployment rate facing $t$ workers is higher than the official unemployment rate facing $x$ workers; $u_{t}^{o}>u_{x}^{o}$ if and only if $\left(s+\lambda_{t}^{I}\right) /\left(s+\lambda_{t}^{F}+\lambda_{t}^{I}\right)>$ $\left(s+\lambda_{x}^{I}\right) /\left(s+\lambda_{x}^{F}+\lambda_{x}^{I}\right)$. This holds if an only if $\lambda_{x}^{F}\left(s+\lambda_{t}^{I}\right)>\lambda_{t}^{F}\left(s+\lambda_{x}^{I}\right)$, which is true when $\lambda_{x}^{F}>\lambda_{t}^{F}$ and $\lambda_{x}^{I}>\lambda_{t}^{I}$, that is, when $\kappa_{t}>\kappa_{x}$. 
Impact of higher punishment on sector allocation (Proposition 2)

Raising the audit rate $p_{l}$ or the punishment fee $\alpha$ increases the wedge, $\psi_{l}=$ $\left(1+p \alpha+\kappa_{l}\right) /(1+z)$. Differentiating Eqs. (35), (36), and (32) with respect to $\psi_{l}$ gives around the equilibrium

$$
\begin{aligned}
& \frac{d \theta^{F}}{d \psi_{l}}=\frac{\frac{(1-\gamma)}{\left(1-\sigma_{l}^{I}\right)} \frac{1}{2} \frac{k \theta_{l}^{F}}{\left(1-\sigma_{l}^{I}\right)^{1-\gamma}}\left(1+\frac{k \theta_{l}^{I}}{\left(\sigma_{l}^{I}\right)^{1-\gamma}}\right) \frac{1}{\theta_{l}^{I}} \frac{1}{\psi_{l}}>0}{\frac{d \theta^{I}}{d \psi_{l}}}=\frac{-\frac{(1-\gamma)}{\left(\sigma_{l}^{I}\right)} \frac{1}{2}\left(1+\frac{k \theta_{l}^{F}}{\left(1-\sigma_{l}^{I}\right)^{1-\gamma}}\right) \frac{1}{\theta_{l}^{F}} \frac{k \theta_{l}^{I}}{\left(\sigma_{l}^{I}\right)^{1-\gamma}} \frac{1}{D_{l}}>0}{\frac{d \sigma_{l}^{I}}{d \psi_{l}}}=\frac{-\frac{1}{2} \frac{1}{\theta_{l}^{F} \theta_{l}^{I}}\left(1+\frac{k \theta_{l}^{F}}{\left(1-\sigma_{l}^{I}\right)^{1-\gamma}}\right) \frac{1}{2}\left(1+\frac{k \theta_{l}^{I}}{D_{l}}\right)}{\left(\sigma_{l}^{I}\right)^{1-\gamma}} \frac{1}{\psi_{l}}<0,
\end{aligned}
$$

where

$$
\begin{aligned}
D_{l}= & \frac{(1-\gamma)}{4 \theta_{l}^{F} \theta_{l}^{I}} \frac{1}{\left(1-\sigma_{l}^{I}\right) \sigma_{l}^{I}}\left\{\left(1+\frac{k \theta_{l}^{I}}{\frac{y_{l}^{F}}{y_{l}^{I}} \psi_{l}\left(\sigma_{l}^{I}\right)^{1-\gamma}}\right)\left(1-\frac{k \theta_{l}^{I}}{\left(\sigma_{l}^{I}\right)^{1-\gamma}}\right)\left(1-\sigma^{I}\right)\right. \\
& \left.+\sigma_{l i}^{I}\left(1-\frac{k \theta_{l}^{I}}{\frac{y_{l}^{F}}{y_{l}^{I}} \psi_{l}\left(\sigma_{l}^{I}\right)^{1-\gamma}}\right)\left(1+\frac{k \theta_{l}^{I}}{\left(\sigma_{l i}^{I}\right)^{1-\gamma}}\right)\right\}
\end{aligned}
$$

which is positive. Hence, as $\lambda_{l i}^{I}=\left(\sigma_{l i}^{I}\right) \gamma\left(\theta_{l}^{I}\right)^{\frac{1}{2}}$ and $\lambda_{l i}^{F}=\left(1-\sigma_{l i}^{I}\right)^{\gamma}\left(\theta_{l}^{F}\right)^{\frac{1}{2}}$, by inspection of Eq. (38), it follows that $d n_{l}^{F} / d \psi_{l}>0, d n_{l}^{I} / d \psi_{l}<0, l=m, h$. The impact on wages is then

$$
\begin{aligned}
& \frac{d \omega_{l}^{F}}{d \psi_{l}}=\frac{1}{2} y_{l}^{F} k \frac{\frac{\theta_{l}^{F}}{\left(1-\sigma_{l i}^{I}\right)^{1-\gamma}}}{d \psi_{l}}, l=m, h, \\
& \frac{d \omega_{l}^{I}}{d \psi_{l}}=\frac{1}{2} y_{l}^{I} k \frac{d \frac{\theta_{l}^{I}}{\left(\sigma_{l i}^{I}\right)^{1-\gamma}}}{d \psi_{l}}, l=m, h,
\end{aligned}
$$

as

$$
\begin{aligned}
\frac{d \frac{\theta_{l}^{F}}{\left(1-\sigma_{l}\right)^{1-\gamma}}}{d \psi_{l}} & =\frac{d \theta_{l}^{F}\left(1-\sigma_{l}\right)^{\gamma-1}}{d \psi_{l}}=\theta_{l}^{F}\left(1-\sigma_{l}\right)^{\gamma-1}\left(\frac{1}{\theta_{l}^{F}} \frac{d \theta_{l}^{F}}{d \psi_{l}}+(1-\gamma)\left(1-\sigma_{l}\right)^{-1} \frac{d \sigma^{I}}{d d \psi_{l}}\right)= \\
& =-\frac{\left(1-\sigma_{l}\right)^{\gamma-1}}{4 D_{l} \psi_{l}} \frac{1-\gamma}{1-\sigma_{l}^{I}}\left(1+\frac{k \theta_{l}^{I}}{\left(\sigma_{l}^{I}\right)^{1-\gamma}}\right) \frac{1}{\theta_{l}^{I}}\left(1-\frac{k \theta_{l}^{F}}{\left(1-\sigma_{l}^{I}\right)^{1-\gamma}}\right)<0 .
\end{aligned}
$$

and

$$
\begin{aligned}
& \frac{d \frac{\theta_{l}^{I}}{\sigma_{l}^{1-\gamma}}}{d \psi_{l}}=\frac{d \theta_{l}^{I}\left(\sigma_{l}\right)^{\gamma-1}}{d \psi_{l}}=\theta_{l}^{I}\left(\sigma_{l}\right)^{\gamma-1}\left(\frac{1}{\theta_{l}^{I}} \frac{d \theta_{l}^{I}}{d \psi_{l}}-(1-\gamma)\left(\sigma_{l}\right)^{-1} \frac{d \sigma^{I}}{d \psi_{l}}\right)= \\
& =-\frac{\left(\sigma_{l}\right)^{\gamma-1}}{4 D_{l} \psi_{l}} \frac{1-\gamma}{\sigma_{l}^{I}}\left(1-\frac{k \theta_{l}^{I}}{\left(\sigma_{l}^{I}\right)^{1-\gamma}}\right) \frac{1}{\theta_{l}^{F}}\left(1+\frac{k \theta_{l}^{F}}{\left(1-\sigma_{l}^{I}\right)^{1-\gamma}}\right)<0 .
\end{aligned}
$$


Impact of higher punishment on unemployment rates (Proposition 3)

Raising the audit rate $p$ or the punishment fee $\alpha$ increases the wedge, $\psi_{l}=$ $\left(1+p \alpha+\kappa_{l}\right) /(1+z)$. Differentiating Eq. (39) with respect to $\psi_{l}$ gives

$$
\frac{d u_{l}}{d \psi_{l}}=-\frac{s}{\left(s+\lambda_{l}^{I}+\lambda_{l}^{F}\right)^{2}}\left(\frac{d \lambda_{l}^{F}}{d \psi_{l}}+\frac{d \lambda_{l}^{I}}{d \psi_{l}}\right)
$$

where

$$
\begin{aligned}
& \frac{d \lambda_{l}^{F}}{d \psi_{l}}+\frac{d \lambda_{l}^{I}}{d \psi_{l}}=\frac{d\left(1-\sigma_{l}^{I}\right)^{\gamma}\left(\theta_{l}^{F}\right)^{\frac{1}{2}}+d\left(\sigma_{l}^{I}\right)^{\gamma}\left(\theta_{l}^{I}\right)^{\frac{1}{2}}}{d \psi_{l}} \\
& \gamma\left(-\left(1-\sigma_{l}^{I}\right)^{\gamma-1}\left(\theta_{l}^{F}\right)^{\frac{1}{2}}+\left(\sigma_{l}^{I}\right)^{\gamma-1}\left(\theta_{l}^{I}\right)^{\frac{1}{2}}\right) \frac{d \sigma_{l}^{I}}{d \psi_{l}} \\
& +\frac{1}{2}\left(\frac{1-\sigma_{l}^{I}}{\left(\theta_{l}^{F}\right)^{\frac{1}{2}}} \frac{d \theta_{l}^{F}}{d \psi_{l}}+\frac{\left(\sigma_{l}^{I}\right)^{\gamma}}{\left(\theta_{l}^{I}\right)^{\frac{1}{2}}} \frac{d \theta_{l}^{I}}{d \psi_{l}}\right)
\end{aligned}
$$

Substituting for the derivatives and the first-order condition for search intensity, we obtain that $d u_{l} / d \psi_{l}$ has the same sign as

$$
\begin{aligned}
& \gamma\left(\frac{1}{\left(y_{l}^{F} / y_{l}^{I}\right) \psi_{l}} \frac{1}{\left(\theta_{l}^{F}\right)^{\frac{1}{2}}}-\frac{1}{\left(\theta_{l}^{I}\right)^{\frac{1}{2}}}\right)\left(1+\frac{1}{\left(y_{l}^{F} / y_{l}^{I}\right) \psi_{l}} \frac{k \theta_{l}^{I}}{\left(\sigma_{l}^{I}\right)^{1-\gamma}}\right)\left(1+\frac{k \theta_{l}^{I}}{\left(\sigma_{l}^{I}\right)^{1-\gamma}}\right) \\
& +(1-\gamma) \frac{k \theta_{l}^{I}}{\left(\sigma_{l}^{I}\right)^{1-\gamma}}\left(\frac{1}{\left(\theta_{l}^{F}\right)^{\frac{1}{2}}} \frac{1}{\left(y_{l}^{F} / y_{l}^{I}\right) \psi_{l}}\left(\frac{1}{\left(y_{l}^{F} / y_{l}^{I}\right) \psi_{l}}+\frac{1}{\left(y_{l}^{F} / y_{l}^{I}\right) \psi_{l}} \frac{k \theta_{l}^{I}}{\left(\sigma_{l}^{I}\right)^{1-\gamma}}\right)\right. \\
& \left.-\frac{1}{\left(\theta_{l}^{I}\right)^{\frac{1}{2}}}\left(1+\frac{1}{\left(y_{l}^{F} / y_{l}^{I}\right) \psi_{l}} \frac{k \theta_{l}^{I}}{\left(\sigma_{l}^{I}\right)^{1-\gamma}}\right)\right)
\end{aligned}
$$

Hence,

$$
\frac{d u_{l}}{d \psi_{l}} \lesseqgtr 0 \text { if and only if }\left(y_{l}^{F} / y_{l}^{I}\right) \psi_{l} \lesseqgtr 1 .
$$

The impact on the official unemployment rate resulting from an increase in the audit rate or the punishment fee corresponds to

$$
\frac{d u_{l}^{o}}{d \psi_{l}}=\frac{\left(s+\lambda_{l}^{I}+\lambda_{l}^{F}\right) \frac{d \lambda_{l}^{I}}{d \psi_{l}}-\left(s+\lambda_{l}^{I}\right)\left(\frac{d \lambda_{l}^{F}}{d \psi_{l}}+\frac{d \lambda_{l}^{I}}{d \psi_{l}}\right)}{\left(s+\lambda_{l}^{I}+\lambda_{l}^{F}\right)^{2}}=\frac{\lambda_{l}^{F} \frac{d \lambda_{l}^{I}}{d \psi_{l}}-\left(s+\lambda_{l}^{I}\right)\left(\frac{d \lambda_{l}^{F}}{d \psi_{l}}\right)}{\left(s+\lambda_{l}^{I}+\lambda_{l}^{F}\right)^{2}}
$$

Impact of higher punishment on education (Propositions 4 and 5)

A closer examination of (37) reveals that changes in the audit rates or punishment rates affect the share of educated workers, $1-\hat{e}$, through $\psi_{l}$ only, whereas changes in the tax rate, $z$, have a direct effect on $1-\hat{e}$ in addition to the effects working through $\psi_{l}$. Therefore, in order to consider the effects of a fully financed change in the punishment rates on the number of educated workers, we have to account for repercussions on $1-\hat{e}$ following adjustments in the tax rate. However, let us first consider the impact on $1-\hat{e}$ of a change in the tax and expected punishment separately:

$$
\left.\frac{\partial(1-\hat{e})}{\partial(p \alpha)}\right|_{z}=-\frac{k}{c^{\prime}(e)(1+z)}\left(y_{h}^{F} \frac{d \frac{\theta_{h}^{F}}{\left(1-\sigma_{h}^{I}\right)^{1-\gamma}}}{d(p \alpha)}-y_{m}^{F} \frac{d \frac{\theta_{m}^{F}}{\left(1-\sigma_{m}^{I}\right)^{1-\gamma}}}{d(p \alpha)}\right)
$$




$$
\left.\frac{\partial(1-\hat{e})}{\partial z}\right|_{p_{l} \alpha}=-\left.\psi_{l} \frac{\partial(1-\hat{e})}{\partial(p \alpha)}\right|_{z}+\frac{c(\hat{e})}{c^{\prime}(\hat{e})(1+z)}
$$

Using Eq. (43), we obtain

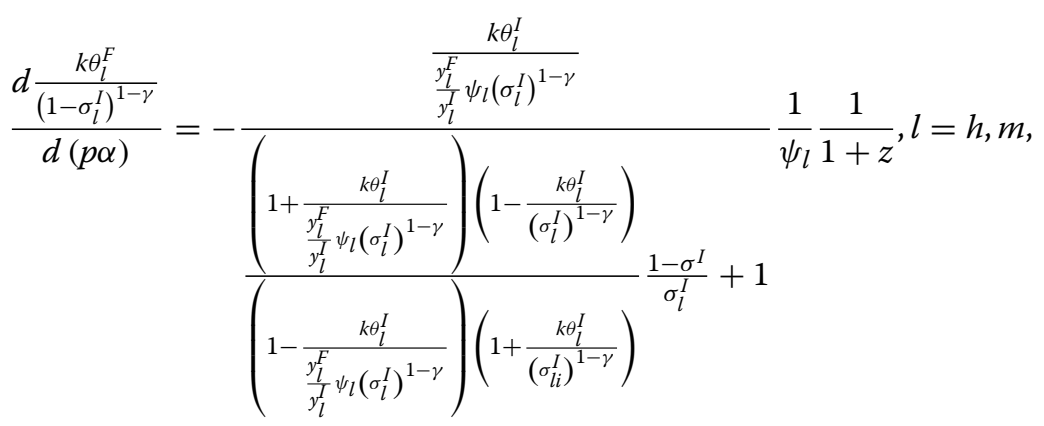

whereby the educational impacts become

$$
\begin{aligned}
& \left.\frac{\partial(1-\hat{e})}{\partial(p \alpha)}\right|_{z}=-\frac{k}{c^{\prime}(e)(1+z)^{2}}\left(y_{h}^{F} \frac{d o_{h}}{d(p \alpha)}-y_{m}^{F} \frac{d o_{m}}{d(p \alpha)}\right) \\
& \left.\frac{\partial(1-\hat{e})}{\partial z}\right|_{p_{l} \alpha}=-\left.\psi_{l} \frac{\partial(1-\hat{e})}{\partial(p \alpha)}\right|_{z}+\frac{c(\hat{e})}{c^{\prime}(\hat{e})(1+z)}
\end{aligned}
$$

where $o_{l}=\frac{1}{\left(y_{l}^{F} / y_{l}^{I}\right) \psi_{l}} \frac{k \theta_{l}^{I}}{\left(\sigma_{l}^{I}\right)^{1-\gamma}}=\frac{k \theta_{l}^{F}}{\left(1-\sigma_{l}^{I}\right)^{1-\gamma}}, l=h, m$ and

$$
\frac{d o_{l}}{d \psi_{l}}=-\frac{\frac{1}{\psi_{l}} o_{l}}{\frac{\left(o_{l}+1\right)\left(1-\left(\frac{y_{l}^{F}}{y_{l}^{I}}\right) \psi_{l} o_{l}\right)}{\left(\frac{y_{l}^{F}}{y_{l}^{I}} \psi_{l} o_{l}+1\right)\left(1-o_{l}\right)} \frac{\left(1-\sigma_{l}^{I}\right)}{\sigma_{l}^{I}}+1}<0, l=h, m .
$$

For existence of an interior solution for education, we need $y_{h}^{F} o_{h}-y_{m}^{F} o_{m}>0$. Hence, education increases if $y_{h}^{F} \frac{d o_{h}}{d \psi_{h}}-y_{m}^{F} \frac{d o_{m}}{d \psi_{m}}>0$. As $\frac{d o_{l}}{d \psi_{l}}, l=h, m$ is negative, and $y_{h}^{F} / y_{m}^{F}>$ $o_{m} / o_{h}$, then for existence of an interior solution for $\hat{e}$, if

$$
\left|\frac{d o_{m}}{d \psi_{m}}\right| /\left|\frac{d o_{h}}{d \psi_{h}}\right|>y_{h}^{F} / y_{m}^{F}>o_{m} / o_{h}
$$

then education increases with $p \alpha$. Consider the case where $\kappa_{h}>\kappa_{m}$. As $\psi_{l}$ increases with $\kappa_{l}$, then for such a solution to exist, we need that $\left|\frac{d o_{l}}{d \psi_{l}}\right|, l=m, h$ is decreasing in concealment costs whereby $\left|\frac{d o_{m}}{d \psi_{m}}\right|>\left|\frac{d o_{h}}{d \psi_{h}}\right|$. We first show that that is the case. Multiply the numerator and denominator by $\psi_{l}$ to obtain

$$
\left|\frac{d o_{l}}{d \psi_{l}}\right|=\frac{o_{l}}{\frac{\left(o_{l}+1\right)\left(1-\left(\frac{y_{l}^{F}}{y_{l}^{I}}\right) \psi_{l} o_{l}\right)}{\left(\frac{y_{l}^{F}}{y_{l}^{I}} o_{l}+\frac{1}{\psi_{l}}\right)\left(1-o_{l}\right)} \frac{\left(1-\sigma_{l}^{I}\right)}{\sigma_{l}^{I}}+\psi_{l}}, l=h, m .
$$


Substituting for the tightness equations, $1-\frac{k \theta_{l}^{F}}{\left(1-\sigma_{l}^{I}\right)^{1-\gamma}}=1-o_{l}=k(r+s+a)\left(\theta_{l}^{F}\right)^{\frac{1}{2}} 2$ and $1-\frac{k \theta_{l}^{I}}{\left(\sigma_{l}^{I}\right)^{1-\gamma}}=1-\left(y_{l}^{F} / y_{l}^{I}\right) \psi_{l} o_{l}=k(r+s+a)\left(\theta_{l}^{I}\right)^{\frac{1}{2}} 2$ and use the fact that $\frac{1-\sigma_{l}^{I}}{\sigma_{l}^{I}}=$ $\left(\frac{\theta_{l}^{F}}{\theta_{l}^{I}}\right)^{\frac{1}{1-\gamma}}\left(\frac{y_{l}^{F}}{y_{l}^{I}} \psi_{l}\right)^{\frac{1}{1-\gamma}}$ according to the search equation to obtain

$$
\left|\frac{d o_{l}}{d \psi_{l}}\right|=\frac{o_{l}}{A_{l}\left(\frac{\theta_{l}^{F}}{\theta_{l}^{I}}\right)^{\frac{1}{1-\gamma}-\frac{1}{2}}\left(\frac{y_{l}^{F}}{y_{l}^{l}} \psi_{l}\right)^{\frac{1}{1-\gamma}}+\psi_{l}}, l=h, m,
$$

where $A_{l}=\frac{\left(o_{l}+1\right)}{\left(\frac{y_{l}^{F}}{y_{l}^{I}} o_{l}+\frac{1}{\psi_{l}}\right)}$. Differentiating (47), $\psi_{l}$, we obtain the following expression for $\frac{d\left|\frac{d o_{l}}{d \psi_{l}}\right|}{d \psi_{l}}:$

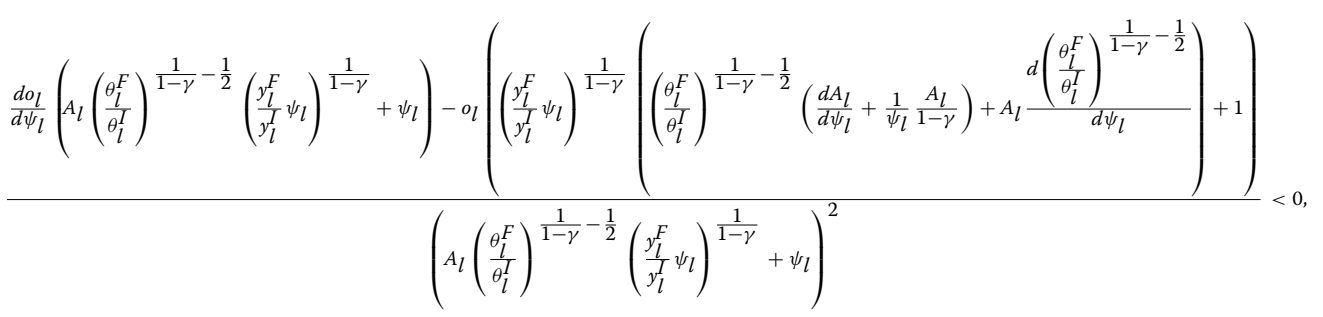

as substituting for $\frac{d o_{l}}{d \psi_{l}}$ using the expression from Eq. (45) gives

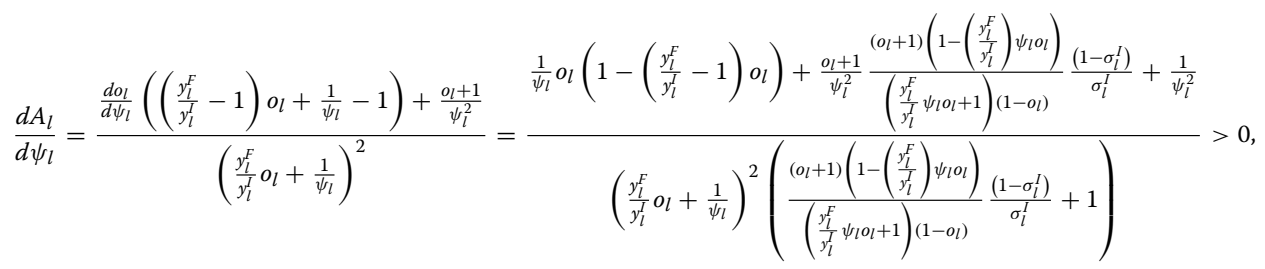

for $\frac{y_{l}^{F}}{y_{l}^{I}}-1<1$ (sufficient condition) and from the equilibrium equations we have $d\left(\theta_{h}^{F} / \theta_{h}^{I}\right) / d \psi_{l}>0$ and $d o_{l} / d \psi_{l}<0$.

Hence, as $\frac{d\left|\frac{d o_{l}}{d \psi_{l}}\right|}{d \psi_{l}}<0$, then $\frac{d\left|\frac{d o_{l}}{d \psi_{l}}\right|}{d \kappa_{l}}<0$, so when $\kappa_{h}>\kappa_{m}$, then $\left|\frac{d o_{m}}{d \psi_{m}}\right|>\left|\frac{d o_{h}}{d \psi_{h}}\right|$. We observe that $\frac{d\left|\frac{d o_{l}}{d \psi_{l}}\right|}{d \psi_{l}}<0$ both because the numerator decreases with $\psi_{l}$ and the denominator increases with $\psi_{l}$. Rewriting the expression determining the sign of $\left.\frac{\partial(1-\hat{e})}{\partial(p \alpha)}\right|_{z}$, Eq. (46) as

$$
\frac{\frac{o_{m}}{A_{m}\left(\frac{\theta_{m}^{F}}{\theta_{m}^{I}}\right)^{\frac{1}{1-\gamma}-\frac{1}{2}}\left(\frac{y_{m}^{F}}{y_{m}^{I}} \psi_{m}\right)^{\frac{1}{1-\gamma}}+\psi_{m}}}{A_{h}\left(\frac{\theta_{h}^{F}}{\theta_{h}^{I}}\right)^{\frac{1}{1-\gamma}-\frac{1}{2}}\left(\frac{y_{h}^{F}}{y_{h}^{I}} \psi_{h}\right)^{\frac{1}{1-\gamma}}+\psi_{h}}=g\left(\kappa_{h}, \kappa_{m}\right) o_{m} / o_{h}>y_{h}^{F} / y_{m}^{F}>o_{m} / o_{h},
$$

where

$$
g\left(\kappa_{h}, \kappa_{m}\right)=\frac{D_{\frac{d o_{h}}{d \psi_{h}}}}{D_{\frac{d o_{m}}{d \psi_{m}}}}=\frac{A_{h}\left(\frac{\theta_{h}^{F}}{\theta_{h}^{I}}\right)^{\frac{1}{1-\gamma}-\frac{1}{2}}\left(\frac{y_{h}^{F}}{y_{h}^{I}} \psi_{h}\right)^{\frac{1}{1-\gamma}}+\psi_{h}}{A_{m}\left(\frac{\theta_{m}^{F}}{\theta_{m}^{I}}\right)^{\frac{1}{1-\gamma}-\frac{1}{2}}\left(\frac{y_{m}^{F}}{y_{m}^{I}} \psi_{m}\right)^{\frac{1}{1-\gamma}}+\psi_{m}}>1,
$$


when $\kappa_{h}>\kappa_{m}$ and $\frac{y_{h}^{F}}{y_{h}^{I}} \geq \frac{y_{m}^{F}}{y_{m}^{I}}$ (or equivalently $\frac{y_{h}^{F}}{y_{m}^{F}} \geq \frac{y_{h}^{I}}{y_{m}^{I}}$ ) as the denominator of $\left|\frac{d o_{l}}{d \psi_{l}}\right|$ increases with $\psi_{l}$. We conclude that if $\frac{y_{h}^{F}}{y_{m}^{F}} \in\left[\frac{o_{m}}{o_{h}}, g\left(\kappa_{h}, \kappa_{m}\right) \frac{o_{m}}{o_{h}}\right]$ education increases with $p \alpha$ and when $\frac{y_{h}^{F}}{y_{m}^{F}} \in\left[g\left(\kappa_{h}, \kappa_{m}\right) \frac{o_{m}}{o_{h}}, \infty\right]$ education falls with $p \alpha$.

Impact of higher punishment on unemployment (Proposition 6)

Raising the audit rate $p$ or the punishment fee $\alpha$ increases the wedge, $\psi_{l}=$ $\left(1+p_{l} \alpha+\kappa_{l}\right) /(1+z)$. Differentiating total unemployment with respect to $\psi_{l}$ gives

$$
\frac{d U_{T O T}}{d \psi_{l}}=\frac{d \hat{e}}{d \psi_{l}}\left(u_{m}-u_{h}\right)+\hat{e} \frac{d u_{m}}{d \psi_{l}}+(1-\hat{e}) \frac{d u_{h}}{d \psi_{l}}
$$

The last two terms are positive $(\leq 0)$ when $\left(y_{l}^{F} / y_{l}^{I}\right) \psi_{l}$ is larger than one $(\leq 1)$. The first term is positive if $\frac{y_{h}^{F}}{y_{m}^{F}} \in\left[\frac{o_{m}}{o_{h}}, g\left(\kappa_{h}, \kappa_{m}\right) \frac{o_{m}}{o_{h}}\right]$ where $g\left(\kappa_{h}, \kappa_{m}\right)>1$ if when $\kappa_{h}>\kappa_{m}$ and $\frac{y_{h}^{F}}{y_{h}^{I}} \psi_{h} \geq \frac{y_{m}^{F}}{y_{m}^{I}} \psi_{m} \geq 1$ as then $\left(u_{m}-u_{h}\right)<(=) 0$ and $\frac{d \hat{e}}{d \psi_{l}}<0$. However, when $\frac{y_{l}^{F}}{y_{l}^{I}} \psi_{l}<1$ and $\kappa_{h}>\kappa_{m}$, then $\left(u_{m}-u_{h}\right)>0$, and in case $\frac{d \hat{e}}{d \psi_{l}}<0$, then unemployment falls, $\frac{d U_{T O T}}{d \psi_{l}}<0$. If, $\frac{y_{h}^{F}}{y_{m}^{F}} \in\left[g\left(\kappa_{h}, \kappa_{m}\right) \frac{o_{m}}{o_{h}}, \infty\right]$, then $\frac{d \hat{e}}{d \psi_{l}}>0$ and $\frac{d U_{T O T}}{d \psi_{l}}$ has an ambiguous sign.

Total official unemployment changes according to

$$
\frac{d U_{T O T}^{o}}{d \psi_{l}}=\frac{d \hat{e}}{d \psi_{l}}\left(u_{m}^{o}-u_{h}^{o}\right)+\hat{e} \frac{d u_{m}^{o}}{d \psi_{l}}+(1-\hat{e}) \frac{d u_{h}^{o}}{d \psi_{l}}<0,
$$

where the last two terms are negative and therefore when $\kappa_{h}>\kappa_{m}$ and $\frac{y_{h}^{F}}{y_{h}^{I}} \psi_{h} \geq \frac{y_{m}^{F}}{y_{m}^{I}} \psi_{m} \geq$ $1 \frac{d U_{T O T}^{o}}{d \psi_{l}}<0$ when $\frac{d \hat{e}}{d \psi_{l}} \leq 0$, as $\left(u_{m}^{o}-u_{h}^{o}\right)>0$. When $\frac{d \hat{e}}{d \psi_{l}} \leq 0$, the sign of $\frac{d U_{T O T}^{o}}{d \psi_{l}}$ is ambiguous.

Socially optimal solution for $\theta_{m}^{F}, \theta_{m}^{l}, \theta_{h}^{F}, \theta_{h^{\prime}}^{l}, \sigma_{m}^{l}, \sigma_{h^{\prime}}^{l}, \hat{e}$.

For simplicity, we here let $y_{l}^{F}=y_{l}^{I}, l=h, m$. We make use of a utilitarian welfare function, which is obtained by adding all individuals' steady state flow values of welfare and let $r+a=r_{a}$. This accounts for that both the formal and the informal economy generate welfare in the economy. The social welfare function is written as

$$
W=\hat{e} \tilde{W}_{m}+\int_{\hat{e}}^{1} \tilde{W}_{h} d e,
$$

where

$$
\begin{aligned}
& \tilde{W}_{m}=u_{m} r_{a} U_{m}+\sum_{j=F, I} n_{m}^{j} r_{a} E_{m}^{j}+\sum_{j=F, I} n_{m}^{j} r_{a} J_{m}^{j}+\sum_{j=F, I} v_{m}^{j} r_{a} V_{m}^{j}+n_{m}^{I} r_{a} J_{m}^{l a w}, \\
& \tilde{W}_{h}=u_{h} r_{a} U_{h}+\sum_{j=F, I} n_{h}^{j} r_{a} E_{h}^{j}+\sum_{j=F, I} n_{h}^{j} r_{a} J_{h}^{j}+\sum_{j=F, I} v_{h}^{j} r_{a} V_{h}^{j}+n_{h}^{I} r_{a} J_{h}^{l a w}-c(e) .
\end{aligned}
$$

We assume that firms are owned by renters who do not work. This explains the presence of $\sum_{j=F, I} n_{m}^{j} r_{a} J_{m}^{j}+\sum_{j=F, I} v_{m}^{j} r_{a} V_{m}^{j}$ and $\sum_{j=F, I} n_{h}^{j} r_{a} J_{h}^{j}+\sum_{j=F, I} v_{h}^{j} r_{a} V_{h}^{j}$ in the welfare function. Moreover, we assume that the concealment costs for tax evasion-facing firms are payments to "lawyers" who only engage in concealing taxable income for other firms. The welfare function therefore includes $n_{m}^{I} r_{a} J_{m}^{\text {law }}=n_{m}^{I} w_{m}^{I} \kappa_{m}$ and $n_{h}^{I} r_{a} J_{h}^{\text {law }}=n_{h}^{I} w_{h}^{I} \kappa_{h}$. This assumption enables us to disregard from the waste associated with tax evasion if firms only pay these expenses to nobody. 
By making use of the asset equations, imposing the flow equilibrium conditions as well as the government budget restriction in (40), and considering the case of no discounting, i.e. $r+a \rightarrow 0$, we can write the welfare function as

$$
\begin{aligned}
& W=\hat{e} W_{m}+\int_{\hat{e}}^{1} W_{h} d e, \\
& W_{m}=\left(1-u_{m}\right) y_{m}-u_{m} k y_{m} \Theta_{m}, \\
& W_{h}=\left(1-u_{h}\right) y_{h}-u_{h} k y_{h} \Theta_{h}-c(e),
\end{aligned}
$$

where $\Theta_{l}=\left(1-\sigma_{l}^{I}\right)^{\gamma} \theta_{l}^{F}+\left(\sigma_{l}^{I}\right)^{\gamma} \theta_{l}^{I}, l=m, h$. This welfare measure is analogous to the welfare measure described in, for example, Pissarides (2000) as it includes aggregate production minus total vacancy costs, i.e. note that $u_{l} \Theta_{l} k=\left(v_{l}^{F}+v_{l}^{I}\right) k, l=m, h$. With the assumption of risk neutral individuals, we ignore distributional issues and hence wages will not feature in the welfare function. We have to find the socially optimal choice of audit rates for the sector employing manual workers and the sector employing highly educated workers; the welfare function in (49)-(51) is maximized by choice of $p_{m}$ and $p_{h}$ subject to the market reactions given by (32), (35), (36), (37), and (39) and the government budget restriction in (40). This yields the following first-order conditions:

$$
\begin{aligned}
& \frac{d W}{d p_{m}}=\hat{e} \frac{d W_{m}}{d \psi_{m}} \frac{d \psi_{m}}{d p_{m}}+\frac{d W}{d(1-e)} \frac{d(1-e)}{d p_{m}}=0 \\
& \frac{d W}{d p_{h}}=(1-\hat{e}) \frac{d W_{h}}{d \psi_{h}} \frac{d \psi_{h}}{d p_{h}}+\frac{d W}{d(1-e)} \frac{d(1-e)}{d p_{h}}=0
\end{aligned}
$$

where $\frac{d W_{l}}{d \psi_{l}}=\left[\sum_{j=F, I} \frac{d W_{l}}{d \theta_{l}^{j}} \frac{d \theta_{l}^{j}}{d \psi_{l}}+\frac{d W_{l}}{d \sigma_{l}^{I}} \frac{d \sigma_{l}^{I}}{d \psi_{l}}\right], j=m, h$. Evaluating the first-order conditions at the levels of $p_{m}$ and $p_{h}$ ensuring that $\psi_{m}=\psi_{h}=1$ turns out to be very convenient and gives

$$
\begin{aligned}
& \left.\frac{d W}{d p_{m}}\right|_{\psi_{m}=1}=\frac{d W}{d(1-\hat{e})} \frac{d(1-\hat{e})}{d p_{m}}>0, \\
& \left.\frac{d W}{d p_{h}}\right|_{\psi_{h}=1}=\frac{d W}{d(1-\hat{e})} \frac{d(1-\hat{e})}{d p_{h}}<0
\end{aligned}
$$

Let us first derive the socially optimal choice of tightness, search, and stock of educated workers by maximizing the welfare function in (49)-(51) with respect to $\theta_{m}^{F}, \theta_{m}^{I}, \theta_{h}^{F}, \theta_{h}^{I}$, $\sigma_{m}^{I}, \sigma_{h}^{I}$, and $\hat{e}$. The socially optimal solution is solved from the following seven conditions:

$$
\begin{aligned}
& \left(\sigma_{l}^{I *}\right)^{(\gamma-1)}-\left(1-\sigma_{l}^{I *}\right)^{\gamma-1}=0, \rightarrow \sigma_{l}^{I *}=\frac{1}{2}, l=m, h, \\
& -s k\left(\theta_{l}^{* I}\right)^{\frac{1}{2}}+\frac{1}{2}\left[1-\frac{k \theta_{l}^{* I}}{\left(\frac{1}{2}\right)^{1-\gamma}}\right]=0, l=m, h, \\
& \left(y_{h}-y_{m}\right) \frac{k \theta_{l}^{* I}}{\left(\frac{1}{2}\right)^{1-\gamma}}-c\left(\hat{e}^{*}\right)=0 .
\end{aligned}
$$

From the first-order conditions for tightness in the formal and informal sector for manual and highly educated workers, i.e. $\frac{\partial W}{\partial \theta_{l}^{I}}=0, \frac{\partial W}{\partial \theta_{l}^{F}}=0, l=F, I$, we get the following conditions: $2 s k\left(\theta_{l}^{I}\right)^{\frac{1}{2}}=u_{l}\left[1+k \Theta_{l}\right]$ and $2 s k\left(\theta_{l}^{F}\right)^{\frac{1}{2}}=u_{l} l=m, h$, which gives $\theta_{l}^{F}=\theta_{l}^{I}$. 
Substitute $\theta_{l}^{F}=\theta_{l}^{I}$ into the first-order condition for search effort, $\frac{\partial W}{\partial \sigma_{l}^{I}}=0$, and the following condition determines the social optimal level of search: $\left(\sigma_{m}^{I}\right)^{\gamma-1}-\left(1-\sigma_{m}^{I}\right)^{\gamma-1}=0$. This yields $\sigma_{l}^{I}=\frac{1}{2}, l=m, h$. Substitute $\sigma_{l}^{I}=\frac{1}{2}, l=m, h$ into $2 s k\left(\theta_{l}^{I}\right)=u_{l}\left[1+k \Theta_{l}\right]$ and $2 s k\left(\theta_{l}^{F}\right)^{\frac{1}{2}}=u_{l}\left[1+k \Theta_{l}\right], l=m, h$, which yields the four equations in (57) determining $\theta_{m}^{F}, \theta_{m}^{I}, \theta_{h}^{F}$, and $\theta_{h}^{I}$ in equilibrium. The socially optimal educational stock is determined by $\partial W / \partial(1-\hat{e})=W_{h}(\hat{e})-W_{m}=y_{h}\left[1-u_{h}\left[1+k \Theta_{h}\right]\right]-y_{m}\left[1-u_{m} y_{m}\left[1+k \Theta_{m}\right]\right]-$ $c(\hat{e})=0$. Now use the equations determining the optimal levels of tightness, $2 s k\left(\theta_{l}^{I}\right)^{\frac{1}{2}}=$ $u_{l} \backslash$ right $]$ and $2 s k\left(\theta_{l}^{F}\right)^{\frac{1}{2}}=u_{l}\left[1+k \Theta_{l}\right], l=m, h$, and the equation for the optimal educational level given by (58). To show that we have a global maximum, we differentiate $W$ with respect to $\sigma_{l}^{I}, \theta_{l}^{I}, \theta_{l}^{F}, l=m, h$ and $1-\hat{e}$ to obtain

$$
\begin{aligned}
& \left(\sigma_{l}^{I *}\right)^{\gamma-1}-\left(1-\sigma_{l}^{I *}\right)^{\gamma-1}=0, l=m, h, \\
& -s k\left(\theta_{l}^{* I}\right)^{\frac{1}{2}}+\frac{1}{2}\left[1-\frac{k \theta_{l}^{* I}}{\sigma^{1-\gamma}}\right]=0, l=m, h, \\
& -s k\left(\theta_{l}^{* F}\right)^{\frac{1}{2}}+\frac{1}{2}\left[1-\frac{k \theta_{l}^{* F}}{(1-\sigma)^{1-\gamma}}\right]=0, l=m, h, \\
& \left(y_{h} \frac{k \theta_{h}^{* I}}{\left(\sigma_{h}^{I}\right)^{1-\gamma}}-y_{m} \frac{k \theta_{m}^{* I}}{\left(\sigma_{m}^{I}\right)^{1-\gamma}}\right)-c\left(\hat{e}^{*}\right)=0 .
\end{aligned}
$$

The associated Hessian matrix is then

$\begin{array}{|ccccccc|}(\gamma-1) S_{m} & 0 & 0 & 0 & 0 & 0 & 0 \\ -\frac{k \theta_{m}^{I}}{2\left(\sigma_{m}^{I}\right)^{2-\gamma}}(\gamma-1) & \Delta_{m}^{I} & 0 & 0 & 0 & 0 & 0 \\ \frac{k \theta_{m}^{F}}{2\left(1-\sigma_{m}^{I}\right)^{2-\gamma}} & 0 & \Delta_{m}^{F} & 0 & 0 & 0 & 0 \\ 0 & 0 & 0 & (\gamma-1) S_{h} & 0 & 0 & 0 \\ 0 & 0 & 0 & -\frac{k \theta_{h}^{I}}{2\left(\sigma_{h}^{I}\right)^{2-\gamma}}(\gamma-1) & \triangle_{h}^{I} & 0 & 0 \\ 0 & 0 & 0 & \frac{k \theta_{h}}{2\left(1-\sigma_{h}^{I}\right)^{2-\gamma}}(\gamma-1) & 0 & \triangle_{h}^{F} & 0 \\ -y_{m}(\gamma-1) \frac{k \theta_{m}^{* I}}{\left(\sigma_{m}^{I}\right)^{2-\gamma}}-y_{m} k\left(\sigma_{m}^{I}\right)^{\gamma-1} & 0 & (\gamma-1) y_{h} \frac{k \theta_{h}^{* I}}{\left(\sigma_{h}^{I}\right)^{2-\gamma}} & y_{h} k\left(\sigma_{h}^{I}\right)^{\gamma-1} & 0 & c^{\prime}\left(\hat{e}^{*}\right)\end{array} \mid$

where $S_{l}=\left(\left(\sigma_{l}^{I}\right)^{\gamma-2}+\left(1-\sigma_{l}^{I}\right)^{\gamma-2}\right), \quad l=m, h, \Delta_{l}^{I}=-\frac{1}{2}\left(s k\left(\theta_{l}^{I}\right)^{-\frac{1}{2}}+k\left(\sigma_{l}^{I}\right)^{\gamma-1}\right)$, $l=m, h$ and $\Delta_{l}^{F}=-\frac{1}{2}\left(s k\left(\theta_{l}^{F}\right)^{-\frac{1}{2}}+k\left(1-\sigma_{l}^{I}\right)^{\gamma-1}\right), \quad l=m, h$. Therefore, $H_{1}=(\gamma-1)\left(\left(\sigma_{m}^{I}\right)^{\gamma-2}+\left(1-\sigma_{m}^{I}\right)^{\gamma-2}\right)<0$ and the principal minors alternate in sign, for all variable values, i.e. $H_{2}=-(\gamma-1)\left(\left(\sigma_{m}^{I}\right)^{\gamma-2}+\left(1-\sigma_{m}^{I}\right)^{\gamma-2}\right) \Delta_{m}^{I}>0, \ldots, H_{7}=$ $(\gamma-1)\left(\left(\sigma_{m}^{I}\right)^{\gamma-2}+\left(1-\sigma_{m}^{I}\right)^{\gamma-2}\right) \Delta_{m}^{I} \Delta_{m}^{F}(\gamma-1)\left(\left(\sigma_{h}^{I}\right)^{\gamma-2}+\left(1-\sigma_{h}^{I}\right)^{\gamma-2}\right) \Delta_{h}^{I} \Delta_{h}^{F} c^{\prime}\left(\hat{e}^{*}\right)$ $<0$, by which we have a global maximum.

\section{Optimal does not induce the socially efficient stock of education (Corollary 8)}

Evaluating (52) and (53) at $p_{m}^{e}$ and $p_{h}^{e}$ such that the socially optimal level of education is reached, i.e. $\frac{d W}{d(1-e)}=0$. From Proposition 7, this requires that $\psi_{m}^{e}>1>$ $\psi_{h}^{e}$. This yields $\left.\frac{d W}{d p_{m}} \quad\right|_{m} ^{e}>1=\hat{e}\left[\frac{d W}{d \theta_{m}^{F}} \frac{d \theta_{m}^{F}}{d \psi_{m}}+\frac{d W}{d \theta_{m}^{I}} \frac{d \theta_{m}^{I}}{d \psi_{m}}+\frac{d W}{d \sigma_{m}^{I}} \frac{d \sigma_{m}^{I}}{d \psi_{m}}\right] \frac{d \psi_{m}}{d p_{m}}$ and $\left.\frac{d W}{d p_{h}}\right|_{\psi_{h}^{e}<1}=$ $(1-\hat{e})\left[\frac{d W}{d \theta_{h}^{F}} \frac{d \theta_{h}^{F}}{d \psi_{h}}+\frac{d W}{d \theta_{h}^{I}} \frac{d \theta_{h}^{I}}{d \psi_{h}}+\frac{d W}{d \sigma_{h}^{I}} \frac{d \sigma_{h}^{I}}{d \psi_{h}}\right] \frac{d \psi_{h}}{d p_{h}}$. From the derivations of the socially optimal 
solution for $\theta_{m}^{F}, \theta_{m}^{I}, \theta_{h}^{F}, \theta_{h}^{I}, \sigma_{m}^{I}, \sigma_{h}^{I}$, it follows that $\left.\frac{d W}{d \theta_{l}^{F}}\right|_{\psi_{l}>1}<0,\left.\frac{d W}{d \theta_{l}^{I}}\right|_{\psi_{l}>1}>0,\left.\frac{d W}{d \sigma_{l}^{I}}\right|_{\psi_{l}>1}>0$ and $\left.\frac{d W}{d \theta_{l}^{F}}\right|_{\psi_{l}<1}>0,\left.\frac{d W}{d \theta_{l}^{I}}\right|_{\psi_{l}<1}<0,\left.\frac{d W_{l}}{d \sigma_{l}^{I}}\right|_{\psi_{l}<1}<0$ as the welfare function is maximized at $\psi_{l}=1$, i.e., $\left.\frac{d W}{d \theta_{l}^{F}}\right|_{\psi_{l}=1}=\left.\frac{d W_{l}}{d \theta_{l}^{I}}\right|_{\psi_{l}=1}=\left.\frac{d W_{l}}{d \sigma l}\right|_{\psi_{l}=1}=0$. It then follows that $\frac{d W}{d p_{m}}$ and $\left.\frac{d W}{d p_{h}}\right|_{\psi_{h}^{e}<1}>0$.

\section{Optimal punishment policy including auditing costs}

The government budget constraint with auditing costs, $\varphi(p)$, is $\frac{z \hat{e} n_{m}^{F} w_{m}^{F}}{1+z}+\frac{p \alpha \hat{e} n_{m}^{I} w_{m}^{I}}{1+p \alpha+\kappa_{m}}+$ $\frac{z(1-\hat{e}) n_{h}^{F} w_{h}^{F}}{1+z}+\frac{p \alpha(1-\hat{e}) n_{m}^{I} w_{h}^{I}}{1+p \alpha+\kappa_{h}}-\varphi(p)=R$, where $p$ is the total intensity of audits, $p=p_{m}+p_{h}$. Adding costs of auditing has no impact on the positive analyses. The welfare function, however, is equal to $W=\hat{e} W_{m}+\int_{\hat{e}}^{1} W_{h} d e-\varphi(p)$, with first-order conditions for optimal audit rates:

$$
\begin{aligned}
& \frac{d W}{d p_{m}}=\hat{e} \frac{d W_{m}}{d \psi_{m}} \frac{d \psi_{m}}{d p_{m}}+\frac{d W}{d(1-e)} \frac{d(1-e)}{d p_{m}}-\varphi^{\prime}(p)=0 \\
& \frac{d W}{d p_{h}}=(1-\hat{e}) \frac{d W_{h}}{d \psi_{h}} \frac{d \psi_{h}}{d p_{h}}+\frac{d W}{d(1-e)} \frac{d(1-e)}{d p_{h}}-\varphi^{\prime}(p)=0,
\end{aligned}
$$

where $\frac{d W_{l}}{d \psi_{l}}=\sum_{j=F, I} \frac{d W_{l}}{d \theta_{l}^{j}} \frac{d \theta_{l}^{j}}{d \psi_{l}}+\frac{d W_{l}}{d \sigma_{l}^{l}} \frac{d \sigma_{l}^{j}}{d \psi_{l}}, j=m, h$. The optimal level of audits is reduced in both sectors. The result from Proposition 7, that welfare is maximized when the government to a larger extent targets its audits to the manual sector, i.e. $p_{m}>p_{h}$ if $\kappa_{h} \geq \kappa_{m}$, will still hold.

\section{Competing interests}

The IZA Journal of Labor Economics is committed to the IZA Guiding Principles of Research Integrity. The authors declare that they have observed these principles.

\section{Acknowledgements}

We want to thank Gerard van den Berg; Per Engström; Tomas Lindström; participants at SAM, EEA, SOLE, CESifo, CIM, and the conference on heterogenous labour: search friction and human capital investments, Konstanz; Lund University; Bristol University; and two anonymous referees.

Responsible editor: Pierre Cahuc

\section{Author details}

${ }^{1}$ Stockholm University, Stockholm, Sweden. ${ }^{2}$ Copenhagen Business School, Frederiksberg, Denmark.

Received: 20 January 2016 Accepted: 3 June 2016

Published online: 12 July 2016

\section{References}

Acemoglu DT (1996) A microfoundation for social increasing returns in human capital accumulation. Q J Econ 61:779-804 Acemoglu D, Shimer R (1999) Holdups and efficiency with search frictions. Int Econ Rev 40:827-849

Albrecht J, Navarro L, Vroman S (2009) The effects of labor market policies in an economy with an informal sector. Econ J 119:1105-1129

Almeida R, Carneiro A (2012) Enforcement of Labor Regulation and Informality. American Economic Journal: Applied Economics 4(3):64-89

Andreoni L, Erard B, Feinstein J (1998) Tax compliance. J Econ Lit 36:818-860

Boeri T, Garibaldi P (2005) Shadow sorting. In: Frankel JA, Pissarides CA (eds). NBER International Seminar on Macroeconomics. University of Chicago Press, Chicago. pp 125-163

Bosch M, Esteban-Pretel J (2012) Job creation and job destruction in the presence of informal markets. J Dev Econ 98(2):270-286

Charlot OL, Decreuse B, Granier P (2005) Adaptability, productivity, and educational incentives in a matching model. Eur Econ Rev 49(4):1007-1032

EC (2007) Undeclared work in the European Union, social affairs and equal opportunities and coordination by Directorate General Communication, Brussels

Fugazza M, Jacques J-F (2004) Labour market institutions, taxation and the underground economy. J Public Econ 88:395-418

Haigner S, Jenewein S, Schneider F, Wakolbinger F (2011) Dissatisfaction, Fear and Annoyance: Driving Forces of Informal Labor Supply and Demand, Discussion Paper, Department of Economics, University of Linz, Austria. Paper presented at the European Public Choice meeting 
Hvidtfeldt C, Jensen B, Larsen C (2011) Undeclared work and the Danes, University Press of Southern Denmark, June 2010, English summary reported. In: Rockwool Foundation Research Unit, March 2011, Copenhagen, Denmark

Kleven H, Knudsen M, Kreiner C, Pedersen S, Saez E (2011) Unwilling or unable to cheat? Evidence from a tax audit experiment in Denmark. Econometrica 79(3):651-692

Kolm A-S, Larsen B (2006) Wages, unemployment, and the underground economy. In: Agell J, Sørensen PB (eds). Tax Policy and Labor Market Performance. MIT press, Cambridge, Massachusetts

La Porta R, Shleifer A (2014) Informality and Development. Journal of Economic Perspectives 28(3):109-26

Meghir C, Narita R, Robin J-M (2015) Wages and informality in developing countries. Am Econ Rev 105(4):1509-1546

OECD (2012) The global forum on transparancy and exchange of information for tax purposes, Tax Tranparency 2012 Report on progress. OECD, Paris

Pedersen S, Smith N (1998) Sort arbejde og sort løn i Danmark (Black Activities and Black Wages in Denmark). National Økonomisk Tidskrift no. 136, Copenhagen, Denmark:289-314

Pedersen S (2003) The Shadow Economy in Germany, Great Britain and Scandinavia-a measurement based on questionnaire surveys. The Rockwool Foundation Research Unit, Study no 10, Copenhagen, Denmark

Pissarides C (2000) Equilibrium search theory. MIT Press, Cambridge

Submit your manuscript to a SpringerOpen ${ }^{\circ}$ journal and benefit from:

- Convenient online submission

- Rigorous peer review

- Immediate publication on acceptance

- Open access: articles freely available online

- High visibility within the field

Retaining the copyright to your article

Submit your next manuscript at $\boldsymbol{\wedge}$ springeropen.com 